\title{
QUANTITATIVE ASPECTS OF THE REACTION BETWEEN INSULIN AND INSULIN-BINDING ANTIBODY
}

\author{
By SOLOMON A. BERSON AND ROSALYN S. YALOW
}

(From the Radioisotope Service, Veterans Administration Hospital, Bronx, N. Y.)

(Submitted for publication May 18, 1959; accepted July 16, 1959)

The presence of insulin-binding antibodies in the serums of insulin-treated subjects has been reported previously (1). With $\mathrm{I}^{131}$-labeled insulin it has been shown that the antigen-antibody complexes do not precipitate, that the binding of insulin to antibody is a reversible process, and that, at constant antibody concentration, the ratio of bound insulin to free insulin is an inverse function of the concentration of insulin (1).

In the present studies, experimental data on the reaction between insulin and insulin-binding antibody are tested against several theoretical models. The results are most compatible with a model composed of a univalent insulin reacting with two distinctly different orders of antibody sites. Data for equilibrium constants, forward and reverse velocity constants and various thermodynamic constants are presented in terms of the model chosen.

\section{METHODS}

Antiserums were obtained from insulin-treated diabetic and schizophrenic subjects generally at least 24 hours and frequently many weeks following the last injection of insulin and were stored frozen or at $4^{\circ} \mathrm{C}$. for weeks or months prior to use.

Insulin- $\mathrm{I}^{131}$ was prepared from crystalline beef insulin ${ }^{1}$ with specific activities of 10 to $100 \mathrm{mc}$. per mg. Methods employed in preparation and in protection of the insulin against extensive radiation damage have been described $(2,3)$. However, because of the extremely high specific activities of the preparations and the trauma incident to the labeling procedure, storage and dilution, occasionally as much as 10 per cent of the insulin- $I^{131}$ was damaged by the time of use. Recent preparations, with which the bulk of the quantitative data has been obtained, have uniformly contained less than 5 per cent damaged components.

All dilutions were made in water or veronal buffer, ${ }^{2}$ 0.1 ionic strength, $\mathrm{pH} 8.6$, to which was added 2 per cent

${ }^{1}$ We are indebted to Dr. O. K. Behrens and Dr. C. W. Pettinga of the Eli Lilly laboratories for generous supplies of crystalline beef insulin.

${ }^{2}$ No significant differences in binding were detected when duplicate specimens of the same antiserum were diluted in water and in veronal. serum albumin to minimize losses of insulin or antibody by adsorption on glassware.

Two types of experiments were performed. In one, henceforth termed "equilibrium state" studies, various relative concentrations of antiserum and insulin, including tracer quantities of insulin- $\mathrm{I}^{131}$, were incubated together at $37^{\circ} \mathrm{C}$. The mixtures were allowed to come to equilibrium and were then analyzed for their content of free and bound insulin. No differences in the binding of insulin- $\mathrm{I}^{131}$ and unlabeled crystalline insulin could be detected, i.e., at any particular insulin concentration the same degree of binding of insulin- $\mathrm{I}^{131}$ was observed whether the insulin present was derived solely from the labeled insulin preparation or was primarily unlabeled insulin with only a tracer amount of insulin- ${ }^{131}$. In the other type of experiment, frequently called "rate" studies but herein termed "transient state" studies, insulin and whole or diluted antiserum were each allowed to come to temperature equilibrium at $37^{\circ} \mathrm{C}$. and then mixed together. The reaction mixtures were analyzed at intervals to determine the rate of formation of insulin-antibody complexes ("association"). The reverse reaction ("dissociation") was studied by adding high concentrations of nonradioactive insulin to the incubation mixtures; thus, insulin-I ${ }^{131}$ dissociating from preformed insulin-antibody complexes was competitively inhibited from recombination with antibody.

The distribution of insulin- $I^{131}$ between free and bound fractions was determined by paper chromatographic methods which have been described previously (1). In brief, these methods depend on the adsorption of free insulin to the paper at the site of application ("origin") while insulin bound to antibody migrates with the serum proteins. It has been noted previously (1) that during paper electrophoresis at $20^{\circ} \mathrm{C}$., in runs lasting 18 to 24 hours, the paper may adsorb some of the insulin dissociating from preformed complexes during the run; this results in a "tailing" of insulin- $\mathrm{I}^{131}$ along the path of migration of the complexes so that this procedure does not permit eminently satisfactory separation of the free and bound insulin present initially. However, movement of serum proteins away from the origin, sufficient for resolution of free and bound insulin, can be effected within 20 to 30 minutes by hydrodynamic flow chromatography combined with electrophoresis (1). Since the rates of both forward and reverse reactions are markedly decreased by lowering the temperature, all chromatographic runs were performed in a cold room at $4^{\circ} \mathrm{C}$. Under these conditions uncomplexed insulin becomes bound to the paper in a fraction of a minute and generally neither the forward nor the reverse reaction occurs to any significant extent after the mixtures are 
applied to the paper strips. ${ }^{3}$ In order to maintain reproducible conditions during chromatography of samples at different serum dilutions, $\mathbf{5 0} \boldsymbol{\mu l}$. of undiluted control plasma was added to all diluted samples at the time of chromatography.

Another method also was used to determine the rates of dissociation of preformed complexes. After incubation of antiserum and insulin- $\mathrm{I}^{131}$, the mixture was added to a source of active "insulinase" (concentrated rat liver homogenate) which is capable of destroying 60 per cent of trace amounts of unbound insulin- $\mathrm{I}^{131}$ in the first minute but does not act on bound insulin (4). The rate of destruction of the insulin- $\mathrm{I}^{131}$ is therefore limited by the rate of dissociation of the complex. The rate of insulin- $\mathrm{I}^{131}$ degradation was evaluated by analysis of aliquots of the mixtures for trichloracetic acid precipitable and nonprecipitable radioactivity (4).

The ability of serum to degrade insulin- $\mathrm{I}^{131}$ on prolonged incubation at $37^{\circ} \mathrm{C}$. has been observed (1). Although many serums are relatively free of such action, some serums are quite troublesome and have to be discarded. Aging and products of hemolysis appear to correlate with the presence of insulin-degrading factors. Whether hemoglobin itself is responsible is not known but since sulfhydryl-containing substances such as $\mathrm{H}_{2} \mathrm{~S}$, cysteine and thioglycollate produce similar changes, it appears possible that reduced glutathione, or - $\mathrm{SH}$ groups of blood proteins are responsible for the changes observed in the insulin- $\mathrm{I}^{131}$. These alterations are characterized by the appearance of I $^{131}$-labeled fractions which bind quite firmly to all serum proteins although mainly to $\alpha_{2}$-globulin (1); deiodination per se is minimal. Damaged fractions produced during the course of preparation of insulin- $\mathrm{I}^{131}$ also bind rather indiscriminately to all serum proteins (1-3). Correction for the nonspecific binding of $I^{131}$-labeled fractions has been made in each experiment by simultaneously running control non-immune plasma samples for evaluation of the

\footnotetext{
${ }^{3}$ When antibody concentration is extremely high as in undiluted serums from insulin-resistant subjects, the forward reaction may continue to a significant extent until the plasma proteins have migrated away from the origin, which may take several minutes. In such cases antibody may actually elute a fraction of the insulin previously adsorbed to the paper. For these reasons and also to slow down the rate of the forward reaction to measurable levels, serums of high antibody titer were always diluted appreciably for transient state studies. Although, after prolonged chromatography, slight elution of insulin, adsorbed to paper by the solvent, can be detected as a broadening of the peak at the origin, the absence of any significant elution under the conditions employed here has been demonstrated in experiments with undiluted control plasma and undamaged insulin- $\mathrm{I}^{131}$ preparations. In these cases there is no detectable radioactivity migrating away from the peak at the origin. The absence of any significant loss of bound insulin- $\mathrm{I}^{131}$ from the complexes by dissociation and adsorption to paper during chromatographic development has also been established by the observation that over 99 per cent of trace insulin-I ${ }^{131}$ migrates with the serum proteins in serums with high antibody titers.
}

damaged moiety in the preparation employed and by electrophoretic analysis for evaluation of "incubation damage." In most experiments these corrections amounted to about 5 per cent of the undamaged insulin- $\mathrm{I}^{131}$. Where damage was significantly in excess of 10 per cent, results are not reported.

Analysis. Since the antigen-antibody complexes under consideration are soluble, direct determination either of the amount of antibody present or of the relative molecular proportions of insulin and antibody in the complexes formed has not been possible. It is necessary, therefore, to consider a number of possible models and to exclude those which are clearly inconsistent with the experimental data. The analysis presented below is employed for this purpose as well as for evaluation of the kinetic data.

The assumption that the law of mass action is applicable to the reactions between antigen and antibody forms the basis of all theoretical considerations which follow.

\section{Equilibrium state studies}

Model: Insulin univalent; single order of antibody combining-sites. Let $[\mathrm{Ag}]$ be the molar concentration of unbound ("free") insulin, $[\mathrm{Ab}]$ the molar concentration of unoccupied antibody combining-sites ${ }^{5}$ of a single order, ${ }^{6}$ 1 Mole of antibody combining-sites being defined as that quantity of antibody capable of binding 1 Mole of insulin, and $[\overline{\mathrm{AgAb}}]$ the molar concentration of bound insulin or occupied antibody combining-sites. Then,

$$
\begin{gathered}
{[\mathrm{Ag}]+[\mathrm{Ab}] \underset{\mathbf{\mathbf { k } ^ { \prime }}}{\stackrel{\mathbf{k}}{\rightleftarrows}}[\overline{\mathrm{AgAb}}]} \\
\mathrm{K}=\frac{\mathbf{k}}{\mathbf{k}^{\prime}}=\frac{[\overline{\mathrm{AgAb}}]}{[\overline{\mathrm{Ag}}][\mathrm{Ab}]}
\end{gathered}
$$

where $K$ is the equilibrium constant and $k$ and $k^{\prime}$ are the forward and reverse velocity constants, respectively.

Let $\left[\mathrm{Ab}^{\circ}\right]$ denote the molar concentration of total antibody combining-sites ${ }^{7}$ so that

$$
\left[\mathrm{Ab}^{\circ}\right]=[\mathrm{Ab}]+[\overline{\mathrm{AgAb}}] .
$$

It follows from Equations 2 and 3 that

$$
\mathrm{K}\left(\left[\mathrm{Ab}^{\circ}\right]-[\overline{\mathrm{AgAb}}]\right)=\frac{[\overline{\mathrm{AgAb}}]}{[\mathrm{Ag}]} .^{8}
$$

${ }^{4}$ Repeated attempts to demonstrate evidence of precipitation after prolonged periods of incubation and refrigeration have been unsuccessful.

${ }^{5}$ Inasmuch as the valency of insulin-binding antibody is not known, the analysis is best formulated in terms of antibody sites rather than in terms of antibody molecules with an assumed valency.

${ }^{6}$ An order of antibody combining-sites is defined, for the purpose of the present study, as a group in which the individual sites are not necessarily identical chemically, but nevertheless exhibit sufficiently small variations in affinity for the antigen as to be indistinguishable under the experimental conditions.

7 Thus, $\left[\mathrm{Ab}^{\circ}\right]=$ valency of antibody $\times$ molar concentration of antibody.

${ }^{8}$ This form is similar to that employed by Scatchard (5) in a study of ion-binding by proteins. 


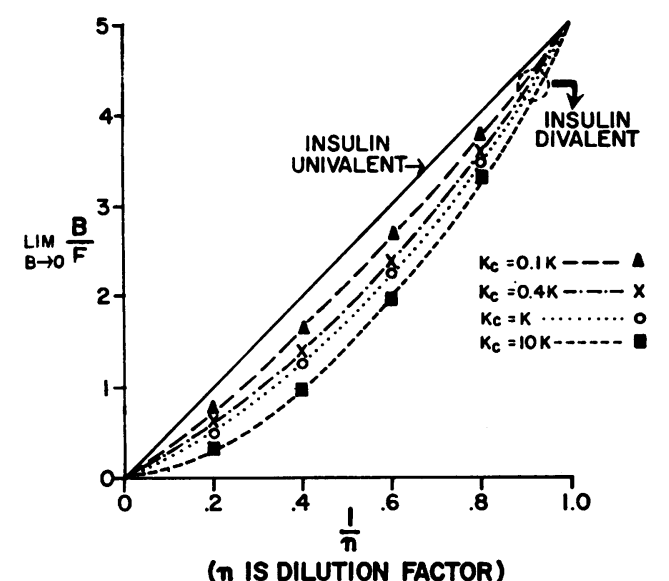

(n IS DILUTION FACTOR)

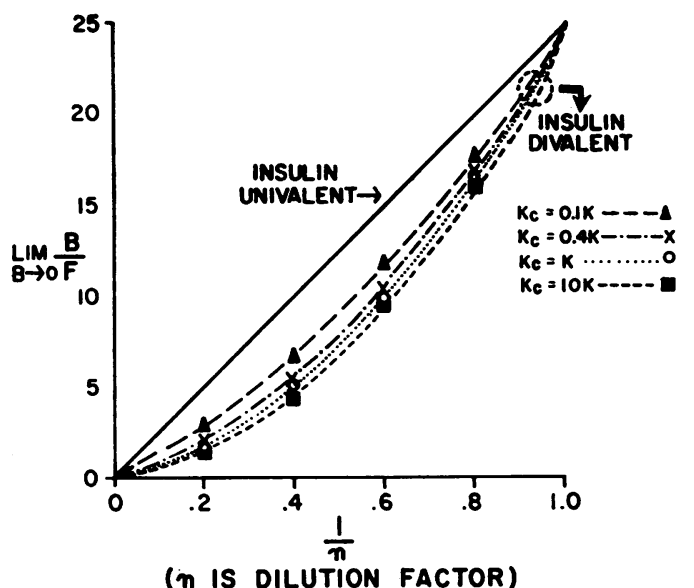

(n IS DILUTION FACTOR)

Fig. 1. Effect of Dilution of Antiserum on $\underset{B \rightarrow 0}{\operatorname{Lim}} \frac{B}{F}$ For Univalent and Divalent Insulin Models AND For Initial $\frac{B}{\mathrm{~F}}$ VAlues of 5 (LefT) AND 25 (Right)

The higher the initial $\frac{B}{F}$ value, the greater the deviation from a straight line for the lower $K_{c} / K$ ratios.

For convenience, let $\mathrm{B}$ and $\mathrm{F}$ represent the molar concentrations offibound insulin $([\overline{\mathrm{AgAb}}])$ and free insulin $([\mathrm{Ag}])$, respectively. Equation 4 may then be rewritten,

$$
\frac{\mathrm{B}}{\mathrm{F}}=\mathrm{K}\left(\left[\mathrm{Ab}^{\circ}\right]-\mathrm{B}\right) \text {. }
$$

The ratio of bound insulin to free insulin is, therefore, a linear function of the concentration of bound insulin and

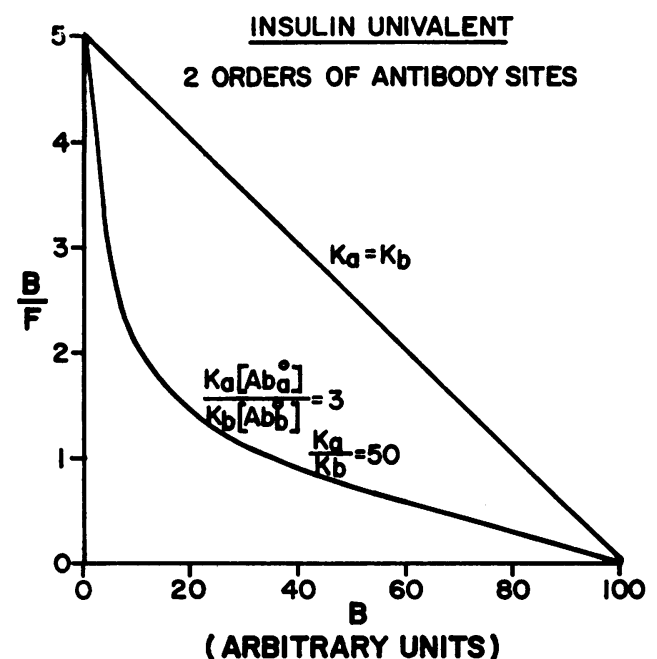

Fig. 2. Schematic Plots of $\frac{B}{\mathrm{~F}}$ vs. B for Univalent Insulin Reacting with Two Orders of Antibody ComBINING-SiTES

Two curves are shown, one for $\mathrm{K}_{\mathrm{a}}=\mathrm{K}_{\mathrm{b}}$, the other for a 50-fold difference in $K_{a}$ and $K_{b}$ and reciprocal 17 -fold difference in antibody concentration (see text). Almost any shaped curve, concave upwards, is possible for this model. a plot of $\frac{B}{F}$ vs. B yields a straight line with a slope of $-K$ and an ordinate intercept of $\mathrm{K}\left[\mathrm{Ab}^{\circ}\right]$.

The total concentration of antibody combining-sites is determined either from the values for $\mathrm{K}$ and $\mathrm{K}\left[\mathrm{Ab}^{\circ}\right]$ or from the intercept with the horizontal axis, since $\left[\mathrm{Ab}^{\circ}\right]$ $=\mathrm{B}$ at $\frac{\mathrm{B}}{\mathrm{F}}=0$.

When insulin concentrations are very low relative to $\left[\mathrm{Ab}^{\circ}\right], \mathrm{B}$ approaches zero and Equation 5 becomes

$$
\operatorname{Lim}_{B \rightarrow 0} \frac{B}{F}=K\left[A b^{\circ}\right] \text {. }
$$

If the concentration of antibody is lowered by serial dilution of the antiserum and $\mathrm{n}$ is the dilution factor,

$$
\operatorname{Lim}_{B \rightarrow 0} \frac{B}{F}=K \frac{\left[\mathrm{Ab}^{\circ}\right]}{n} \text {. }
$$

$\operatorname{Lim}_{B \rightarrow 0} \frac{B}{F}$ is then directly proportional to $\frac{1}{n}$ (Figure 1 ).

Model: Insulin univalent; two or more orders of antibody combining-sites. If insulin is univalent and there are two distinct orders of antibody combining-sites $\left(A b_{a}\right.$ and $\left.A b_{b}\right)$, each with characteristic forward and reverse velocity constants, then,

$$
\begin{aligned}
& {[\mathrm{Ag}]+\left[\mathrm{Ab}_{\mathrm{a}}\right] \underset{\mathbf{k}_{\mathrm{a}^{\prime}}}{\stackrel{\mathrm{k}_{\mathbf{a}}}{\rightleftarrows}}\left[\overline{\mathrm{AgAb}_{\mathrm{a}}}\right]} \\
& {[\mathrm{Ag}]+\left[\mathrm{Ab}_{\mathrm{b}}\right] \underset{\mathbf{k b}^{\prime}}{\stackrel{\mathbf{k}_{\mathrm{b}}}{\rightleftarrows}}\left[\overline{\mathrm{AgAb}_{\mathrm{b}}}\right]}
\end{aligned}
$$

and by rearrangements similar to those of the preceding section, it follows that

$$
\frac{B}{F}=K_{a}\left(\left[\mathrm{Ab}_{a}^{\circ}\right]-B_{a}\right)+K_{b}\left(\left[\mathrm{Ab}_{b}^{\circ}\right]-B_{b}\right)
$$

where $B=B_{a}+B_{b}=\left[\overline{\operatorname{AgAb}_{a}}\right]+\left[\overline{\operatorname{AgAb}_{b}}\right]$, and $K_{a}$ and $\mathrm{K}_{\mathrm{b}}$ are the respective equilibrium constants. 
A plot of $\frac{B}{F}$ vs. B (Figure 2) is a curve, concave upwards, the departure from linearity of which depends on the relative values of the $\mathrm{K}^{\prime} \mathrm{s}$ and $\left[\mathrm{Ab}^{\circ}\right]$ 's. Here the ordinate intercept is $K_{a}\left[\mathrm{Ab}_{\mathrm{a}}^{\circ}\right]+\mathrm{K}_{\mathrm{b}}\left[\mathrm{Ab}_{\mathrm{b}} \mathrm{b}\right.$. If the $\mathrm{K}$ 's are quite similar, the curve will approximate a straight line and it may not be possible to determine the individual K's; the mean $\mathrm{K}$ will approximate that obtained using Equation 5 . If the K's differ significantly, solutions for the two K's and the two $\left[\mathrm{Ab}^{\circ}\right]$ 's may be obtained either 1 ) by curve-fitting with assumed trial values for the K's and [A $\left.{ }^{\circ}\right]^{\prime}$ 's or 2) by substituting experimental values for $\frac{B}{F}$ and $\left(B_{a}+B_{b}\right)$ into Equation 9. Since Equation 9 contains seven variables, only two of which $\left(\frac{B}{F}\right.$ and $\left.B_{a}+B_{b}\right)$ are determined by each point, a minimum of five points is required for solution. The values at the ordinate intercept $(B=0)$ and at the abscissa intercept $\left(B=B_{a}+B_{b}=\left[A^{\circ}{ }_{a}\right]+\left[A^{\circ}{ }_{b}\right]\right)$ provide two points so that values for at least three other points along the curve must be employed. The method of curve-fitting has been found to be more convenient (see Appendix A).

On dilution of the antiserum, at very low insulin concentrations, the ratio $\underset{\mathbf{B} \rightarrow 0}{\operatorname{Lim}} \frac{\mathrm{B}}{\mathbf{F}}$ will again be directly proportional to $\frac{1}{\mathrm{n}}$ (as in Figure 1), according to the following equation:

$$
\begin{aligned}
\operatorname{Lim}_{\mathrm{B} \rightarrow 0} \frac{B}{\mathrm{~F}}=\mathrm{K}_{\mathrm{a}} \frac{\left[\mathrm{Ab}_{\mathrm{a}}^{\circ}\right]}{\mathrm{n}}+\mathrm{K}_{\mathrm{b}} & \frac{\left[\mathrm{Ab}_{\mathrm{b}}{ }_{\mathrm{b}}\right]}{\mathrm{n}} \\
& =\frac{\mathrm{K}_{\mathrm{a}}\left[\mathrm{Ab}_{\mathrm{a}}\right]+\mathrm{K}_{\mathrm{b}}\left[\mathrm{Ab}_{\mathrm{b}}\right]}{\mathrm{n}} .
\end{aligned}
$$

Similar considerations hold for more than two orders of antibody combining-sites.

It is evident that these formulations do not discriminate between a single antibody molecule with more than one order of combining-sites (divalent or multivalent antibody) and different antibody molecules each with a single combining-site of a distinct order. In itself, this distinction is not pertinent to the determination of the equilibrium constants and total binding capacities of the different orders of antibody sites. Nevertheless, some reservation must be held in the case that the two different orders of antibody sites are the two sites on divalent antibody molecules, for then the two equations, $8 \mathrm{a}$ and $8 \mathrm{~b}$, may not be independent; i.e., because of steric or other restrictions, a complexed antigen molecule may interfere with entry of a second antigen molecule, particularly if the combining-sites on the antibody molecule are closely spaced.

Model: Insulin divalent; one or more orders of antibody combining-sites. If a single molecule of insulin is able to complex with two antibody combining-sites and if all antibody combining-sites are of the same order, the following reactions obtain,

$$
\begin{gathered}
{[\mathrm{Ag}]+[\mathrm{Ab}] \underset{\mathbf{k}^{\prime}}{\stackrel{\mathbf{k}}{\rightleftarrows}}[\overline{\mathrm{AgAb}}]} \\
{[\overline{\mathrm{AgAb}}]+[\mathrm{Ab}] \underset{\mathbf{k}_{\mathbf{o}^{\prime}}}{\stackrel{\mathbf{k}_{\mathbf{o}}}{\rightleftarrows}}\left[\overline{\mathrm{AgA \textrm {Ab } _ { 2 }}}\right] .}
\end{gathered}
$$

The formulation is complete if the two antigenic sites are identical. If they differ, two sets of equations, 11 and 12 , are required to take into account the different possible sequences; if, in addition, cross reaction of each antigenic site with antibody to the other site can also occur, description of all possible sequences would involve four sets of paired consecutive reactions. While these possibilities are of interest they would not alter the conclusions derived from the development which follows and will not be ana1 yzed further here. From Equations 11 and 12:

$$
\begin{aligned}
\mathrm{K} & =\frac{\mathrm{k}}{\mathrm{k}^{\prime}}=\frac{[\overline{\mathrm{AgAb}}]}{[\mathrm{Ag}][\overline{\mathrm{Ab}}]} \\
\mathrm{K}_{\mathrm{c}} & =\frac{\mathrm{k}_{\mathrm{e}}}{\mathrm{k}_{\mathrm{c}}{ }^{\prime}}=\frac{[\overline{\mathrm{AgAb}}]}{[\overline{\mathrm{AgAb}}][\mathrm{Ab}]} .
\end{aligned}
$$

Since $[\mathrm{Ab}]=\left[\mathrm{Ab}^{\circ}\right]-[\overline{\mathrm{AgAb}}]-2[\overline{\mathrm{AgAb}}]$ and $\mathrm{B}=$ $[\overline{\mathrm{AgAb}}]+\left[\overline{\mathrm{AgAb}_{2}}\right]$, Equations 13 and 14 may be rewritten, after transposition,

$$
\begin{aligned}
\frac{[\overline{\mathrm{AgAb}}]}{[\mathrm{Ag}]} & =\mathrm{K}\left(\left[\mathrm{Ab}^{\circ}\right]-\mathrm{B}-\left[\overline{\mathrm{AgAb}_{2}}\right]\right) \\
\left.\frac{[\overline{\mathrm{AgAb}}}{[\mathrm{Ag}]}\right] & =\mathrm{KK}_{\mathrm{c}}\left(\left[\mathrm{Ab}^{\circ}\right]-\mathrm{B}-\left[\overline{\mathrm{AgAb}_{2}}\right]\right)^{2}
\end{aligned}
$$

and from the sum of Equations 15 and 16,

$$
\begin{aligned}
\frac{B}{F}=K\left(\left[\mathrm{Ab}^{\circ}\right]-B\right. & \left.-\left[\overline{\mathrm{AgAb}_{2}}\right]\right) \\
+ & K_{K_{c}}\left(\left[\mathrm{Ab}^{\circ}\right]-B-\left[\overline{\mathrm{AgAb}_{2}}\right]\right)^{2} .
\end{aligned}
$$

The ratio, $\frac{\left[\overline{\mathrm{AgAb}_{2}}\right]}{[\overline{\mathrm{AgAb}}]}$, will decrease progressively with increase in insulin concentration. A plot of $\frac{B}{F}$ vs. B is a curve, which is concave upwards, as in Figure 3. The

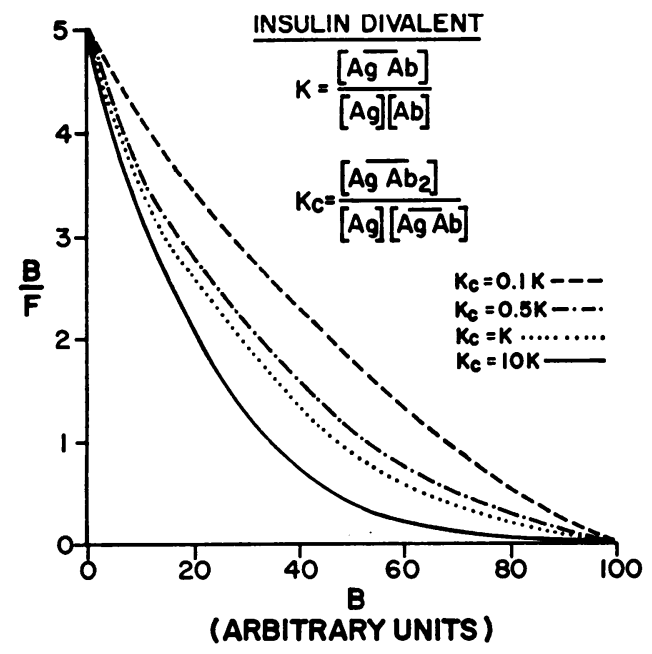

Fig. 3. Schematic Plots of $\frac{B}{F}$ vs. B for Divalent Insulin Reacting with a Single Order of Antibody Combining-Sites at Different $\frac{K_{\mathbf{c}}}{\mathrm{K}}$ Ratios 
ordinate intercept is $\mathrm{K}\left[\mathrm{Ab}^{\circ}\right]+\mathrm{KK}_{\mathrm{c}}\left[\mathrm{Ab}^{\circ}\right]^{2}$, and $\left[\mathrm{Ab}^{\circ}\right]$ is given by the intercept with the horizontal axis. It is evident that such curves may not readily be distinguishable from those shown in Figure 2. However, a distinction between the two models is available from the behavior of $\operatorname{Lim}_{B \rightarrow 0} \frac{B}{F}$ on dilution of the antiserum. At low insulin concentrations, Equation 17 becomes

$$
\begin{aligned}
\operatorname{Lim}_{B \rightarrow 0} \frac{B}{F}=K\left[\mathrm{Ab}^{\circ}\right]+K & {\left[\mathrm{Ab}^{\circ}\right]^{2} } \\
& =K\left[\mathrm{Ab}^{\circ}\right]\left(1+\mathrm{K}_{\mathrm{c}}\left[\mathrm{Ab}^{\circ}\right]\right) .
\end{aligned}
$$

If the antiserum is diluted by the factor $n$,

$$
\begin{aligned}
\operatorname{Lim}_{B \rightarrow 0} \frac{B}{F}=\frac{K\left[\mathrm{Ab}^{\circ}\right]}{n}+K_{C} \frac{\left[\mathrm{Ab}^{\circ}\right]^{2}}{n^{2}} \\
=K \frac{\left[\mathrm{Ab}^{\circ}\right]}{\mathrm{n}}\left(1+\mathrm{K}_{\mathrm{c}} \frac{\left[\mathrm{Ab}^{\circ}\right]}{\mathrm{n}}\right)
\end{aligned}
$$

and $\operatorname{Lim}_{B \rightarrow 0} \frac{B}{F}$ decreases more rapidly than $\frac{1}{n}$ (Figure 1 ). $K$ and $K_{c}$ can be determined from the values for $\operatorname{Lim}_{B \rightarrow 0} \frac{B}{F}$ at any two dilutions if $\left[\mathrm{Ab}^{\circ}\right]$ is determined from data plotted as in Figure 3.

It is necessary to consider further the relationships $\operatorname{Lim}_{B \rightarrow 0} \frac{B}{F}$ vs. $\frac{1}{n}$ and $\frac{B}{F}$ vs. B. Firstly, it is evident from Equation $18 \mathrm{~b}$ that, regardless of the relative magnitudes of $\mathrm{K}$ and $\mathrm{K}_{\mathrm{c}}$, if $\mathrm{K}_{\mathrm{c}}\left[\mathrm{Ab}^{\circ}\right] \gg 1$, the ratio will vary, not with $\frac{1}{n}$ but with $\frac{1}{n^{2}}$. Conversly, when $K_{c}\left[\mathrm{Ab}^{\circ}\right] \ll 1$, a linear relationship between $\operatorname{Lim}_{B \rightarrow 0} \frac{B}{F}$ and $\frac{1}{n}$ is closely approximated. In the latter event, deviation from a linear relationship might escape detection without excluding thereby the possible divalency of insulin.

The influence of the ratio, $\frac{K_{c}}{K}$, on the relationship $\operatorname{Lim}_{B \rightarrow 0} \frac{B}{F}$ vs. $\frac{1}{n}$ is shown in Figure 1 for initial $\underset{B \rightarrow 0}{\operatorname{Lim}} \frac{B}{F}$ values of 5 and 25, respectively. Even for the lower initial $\frac{B}{F}$ value, a significant deviation from linearity is readily apparent when $K_{c} \geqq 0.4 \mathrm{~K}$.

For any given value of $K_{c}$, the ratio, $\operatorname{Lim}_{B \rightarrow 0} \frac{[\overline{\mathrm{AgAb}}]}{[\overline{\mathrm{AgAb}}]}$, is proportional to the antibody concentration since, in the region $\mathrm{B} \rightarrow 0,[\mathrm{Ab}] \cong\left[\mathrm{Ab}^{\circ}\right]$ and therefore, from Equation 14,

$$
\operatorname{Lim}_{B \rightarrow 0} \frac{\left[\overline{\mathrm{AgAb_{2 }}}\right]}{[\overline{\mathrm{AgAb}}]}=K_{c}\left[\mathrm{Ab}^{\circ}\right] .
$$

It is important to note that since the curvature of the $\frac{B}{F}$ vs. $B$ curve (Figure 3 ) increases with increase in the ratio, $\frac{\mathrm{K}_{\mathrm{c}}}{\mathrm{K}}$, a markedly curvilinear relationship for $\frac{\mathrm{B}}{\mathrm{F}}$ vs. $\mathrm{B}$ and an apparently straight line relationship for $\operatorname{Lim}_{B \rightarrow 0} \frac{B}{F}$ vs. $\frac{1}{n}$ are incompatible with a model requiring more than a single valency for insulin.
It may also be observed that a reasonable restriction (though not essential to the analysis) for the relationship of $\mathrm{K}_{\mathrm{c}}$ to $\mathrm{K}$ is that $\mathrm{K}_{\mathrm{c}} \leqq \mathrm{K}$, since it appears unlikely either that a second antibody molecule is more easily complexed than is the first or that the divalent form of the antigenantibody complex, $[\overline{\mathrm{AgAb}}$ ], releases an antibody molecule any less readily than does the univalent form $[\overline{\mathrm{AgAb}}]$. The reverse situation would seem to be the more likely in view of the possibility that through steric or other restrictions, the antibody molecules would interfere with each other's attachment onto the relatively small insulin molecule.

It is readily shown that if insulin is multivalent and there is a single order of antibody sites,

$\operatorname{Lim}_{B \rightarrow 0} \frac{B}{F}=K\left[A b^{\circ}\right]+K_{c}\left[A b^{\circ}\right]$

$\left.+\mathrm{KK}_{\mathrm{c}} \mathrm{K}_{\mathrm{d}}\left[\mathrm{Ab}^{\circ}\right]^{3}+\cdots 20\right)$

Whether or not there are, in addition, several orders of antibody combining-sites, multivalency of antigen will produce deviations from the straight line of Figure 1 on dilution of the antiserum.

\section{Transient state studies}

Model: Insulin univalent. The case of two orders of antibody combining-sites only is presented. From classical chemical kinetics, for the opposing first and second order reactions of Equations $8 \mathrm{a}$ and $\mathrm{b}$,

$$
\begin{aligned}
& \frac{d[\overline{\mathrm{AgAb}}]}{\mathrm{dt}}=k_{\mathrm{a}}[\mathrm{Ag}]\left[\mathrm{Ab}_{\mathrm{a}}\right]-\mathrm{k}_{\mathrm{a}}{ }_{\mathrm{a}}\left[\overline{\mathrm{AgAb_{a }}}\right] \\
& \frac{\mathrm{d}\left[\overline{\mathrm{AgAb_{b }}}\right]}{\mathrm{dt}}=k_{b}[\mathrm{Ag}]\left[\mathrm{Ab}_{\mathrm{b}}\right]-k^{\prime}{ }_{b}\left[\overline{\mathrm{AgAb_{b }}}\right] .
\end{aligned}
$$

If now, $\left[\mathrm{Ab}^{\circ}\right] \gg\left[\mathrm{Ag}^{\circ}\right]$, where $\left[\mathrm{Ag}^{\circ}\right]$ is the initial concentration of insulin, the second order forward reactions in Equations $8 \mathrm{a}$ and $\mathrm{b}$ become pseudo first order, since $\left[\mathrm{Ab}_{\mathrm{a}}\right] \cong\left[\mathrm{Ab}_{\mathrm{a}}^{\circ}\right]$ and $\left[\mathrm{Ab}_{\mathrm{b}}\right] \cong\left[\mathrm{Ab}_{\mathrm{b}}{ }_{\mathrm{b}}\right]$ throughout the course of the reaction. Therefore, under conditions in which only tracer quantities of insulin- $\mathrm{I}^{131}$ are added to antiserum, Equations 21 and 22 become, with the terminology previously employed,

$$
\begin{aligned}
& \frac{\mathrm{dB}_{\mathrm{a}}}{\mathrm{dt}}=\mathrm{k}_{\mathrm{a}}\left[\mathrm{Ab}_{\mathrm{a}}^{\circ}\right] \mathrm{F}-\mathrm{k}_{\mathrm{a}}^{\prime} \mathrm{B}_{\mathrm{a}} \quad\left[\mathrm{Ab}_{\mathrm{a}}^{\circ}\right] \gg\left[\mathrm{Ag}^{\circ}\right], \\
& \frac{\mathrm{dB} \mathrm{b}}{\mathrm{dt}}=\mathrm{k}_{\mathrm{b}}\left[\mathrm{Ab}^{\circ}{ }_{\mathrm{b}}\right] \mathrm{F}-\mathrm{k}_{\mathrm{b}} \mathrm{B}_{\mathrm{b}} \quad\left[\mathrm{Ab}^{\circ}{ }_{\mathrm{b}}\right] \gg\left[\mathrm{Ag}^{\circ}\right] .
\end{aligned}
$$

The sum of Equations 23 and 24 yields

$$
\frac{\mathrm{dB}}{\mathrm{dt}}=\left(\mathrm{k}_{\mathrm{a}}\left[\mathrm{Ab}_{\mathrm{a}}^{\circ}\right]+\mathrm{k}_{\mathrm{b}}\left[\mathrm{Ab}^{\circ}{ }_{\mathrm{b}}\right]\right) \mathrm{F}-\left(\mathrm{k}_{\mathrm{a}}^{\prime} \mathrm{B}_{\mathrm{a}}+\mathrm{k}_{\mathrm{b}} \mathrm{B}_{\mathrm{b}}\right) \text {, }
$$

where, as before, $\mathrm{B}=\mathrm{B}_{\mathrm{a}}+\mathrm{B}_{\mathrm{b}}$.

Since initially there is no $B_{a}$ or $B_{b}$ present and all the insulin is in the free form, at zero time Equation 25 reduces to

$$
\left(\frac{\mathrm{dB}}{\mathrm{dt}}\right)_{\mathrm{t}=0}=\left(\mathrm{k}_{\mathrm{a}}\left[\mathrm{Ab}_{\mathrm{a}}^{\circ}\right]+\mathrm{k}_{\mathrm{b}}\left[\mathrm{Ab}_{\mathrm{b}}\right]\right)\left[\mathrm{Ag}^{\circ}\right]^{9}
$$

${ }^{9}$ Since at zero time, $\left[\mathrm{Ab}_{\mathrm{a}}\right]=\left[\mathrm{Ab}_{\mathrm{a}}\right]$ and $\left[\mathrm{Ab}_{\mathrm{b}}\right]=$ $\left[\mathrm{Ab}_{\mathrm{b}} \mathrm{b}\right.$, Equation 26 is applicable regardless of the initial concentrations of insulin. 
where $\left[\mathrm{Ag}^{\circ}\right]$ may be taken as 1.0 or 100 per cent. Thus, the zero time slope of $B$ vs. $t$ as given by Equation 26 is the fraction or per cent $\left[\mathrm{Ag}^{\circ}\right]$ converted to $\mathrm{B}$ per unit time.

If, at any time during the reaction, further reaction between insulin- $\mathrm{I}^{131}$ and $\mathrm{Ab}$ is inhibited, dissociation of the preformed complexes may be expressed by the following:

$$
\begin{aligned}
\frac{d B_{a}}{d t} & =-k^{\prime}{ }_{a} B_{a} \\
\frac{d B_{b}}{d t} & =-k^{\prime}{ }_{b} B_{b}
\end{aligned}
$$

which become, on integration,

$$
\begin{aligned}
& B_{a}=\bar{B}_{a} e^{-k_{a}^{\prime} t} \\
& B_{b}=\bar{B}_{b} e^{-k^{\prime} b t}
\end{aligned}
$$

where $\overline{\mathrm{B}}_{\mathrm{a}}$ and $\overline{\mathrm{B}}_{\mathrm{b}}$ are the concentrations of bound insulin in the two complexes, respectively, at the time when further combination and reassociation of insulin- $\mathrm{I}^{131}$ and antibody are first inhibited. Therefore,

$$
B_{t}=\bar{B}_{a} e^{-k^{\prime} a t}+\bar{B}_{b} e^{-k^{\prime} b t}
$$

where $B_{t}$ is the concentration of insulin remaining bound at time $t$, and $t$ is time elapsed following inhibition of combination or reassociation.

By resolving the two-component curve of Equation 29 into its separate exponential components (one of which represents a more slowly dissociating, the other a more rapidly dissociating complex), values for $k^{\prime}{ }_{a}, k_{b}^{\prime}, \bar{B}_{a}$ and $\bar{B}_{b}$ are obtained. If the reaction. between insulin and antibody is allowed to reach equilibrium prior to inhibition, then $\operatorname{Lim}_{B \rightarrow 0} \frac{\bar{B}_{a}}{F}=K_{a}\left[A b_{a}^{\circ}\right]$ and $\operatorname{Lim}_{B \rightarrow 0} \frac{\bar{B}_{b}}{F}=K_{b}\left[A b_{b}^{\circ}\right]$ (cf. Equations 6 and 8). Thus the values for each $K\left[\mathrm{Ab}^{\circ}\right]$ may be determined from "dissociation" rate studies and compared with values obtained from equilibrium state analyses $\left(\frac{B}{F}\right.$ vs. $\left.B\right)$.

Also, since from Equation 2,

$$
\begin{aligned}
& K_{a}\left[A b^{\circ}{ }_{a}\right]=\frac{k_{a}\left[A b^{\circ}{ }_{a}\right]}{k_{a}^{\prime}} \\
& K_{b}\left[A b^{\circ}{ }_{b}\right]=\frac{k_{b}\left[A b^{\circ}{ }_{b}\right]}{k_{b}^{\prime}}
\end{aligned}
$$

$k_{a}\left[\mathrm{Ab}^{\circ}{ }_{a}\right]$ and $k_{b}\left[\mathrm{Ab}^{\circ}{ }_{b}\right]$ can be calculated individually from the values for $\mathrm{k}_{\mathrm{a}}^{\prime}, \mathrm{k}_{\mathrm{b}}^{\prime}, \mathrm{K}_{\mathrm{a}}\left[\mathrm{Ab}^{\circ}{ }_{\mathrm{a}}\right]$ and $\mathrm{K}_{\mathrm{b}}\left[\mathrm{Ab}^{\circ}{ }_{\mathrm{b}}\right]$ and compared with the sum, $\mathrm{k}_{\mathrm{a}}\left[\mathrm{Ab}_{\mathrm{a}}{ }_{\mathrm{a}}\right]+\mathrm{k}_{\mathrm{b}}\left[\mathrm{Ab}_{\mathrm{b}}{ }_{\mathrm{b}}\right]$, as determined from the zero time slopes of the forward reaction at low insulin concentrations, employing Equation 26.

If, following the addition of tracer quantities of insulin-I ${ }^{131}$ to antiserum, the reaction mixture is analyzed at intervals for free insulin and for bound insulin in each of the complexes $B_{a}$ and $B_{b}$, another approach may be employed for the determination of the $k\left[\mathrm{Ab}^{\circ}\right]$ 's and the $k^{\prime \prime} s$. The transient state equations may be written:

$$
\begin{aligned}
\frac{d F}{d t} & =-\left(k_{a}\left[A b^{\circ}\right]+k_{b}\left[A b_{b}^{\circ}\right]\right) F+k^{\prime} B_{a}+k^{\prime}{ }_{b} B_{b} \\
\frac{d B_{a}}{d t} & =k_{a}\left[A b^{\circ}\right] F-k^{\prime}{ }_{a} B_{a} \\
\frac{d B_{b}}{d t} & =k_{b}\left[A b^{\circ}\right] F-k_{b}^{\prime} B_{b}
\end{aligned}
$$

where Equations 33 and 34 are identical with Equations 23 and 24 , respectively.

Solution of these equations for $F, B_{a}$ and $B_{b}$ as a function of time, $t$, employing the boundary conditions that at $\mathrm{t}=0 ; \mathrm{F}=1, \mathrm{~B}_{\mathrm{a}}=\mathrm{B}_{\mathrm{b}}=0$ and at $\mathrm{t}=\infty ; \mathrm{F}_{(\mathrm{eq})}+\mathrm{B}_{\mathrm{a}(\mathrm{eq})}$ $+B_{b(e q)}=1$, where $F_{(e q)}, B_{a b(e q)}$ and $B_{b(e q)}$ are the respective equilibrium values, yields;

$$
\begin{aligned}
F & =F_{(e q)}-\left(r_{1}+s_{1}\right) e^{-\lambda_{1} t}-\left(r_{2}+s_{2}\right) e^{-\lambda_{2} t} \\
B_{a} & =B_{a(e q)}+r_{1} e^{-\lambda_{1} t}+r_{2} e^{-\lambda_{2} t} \\
B_{b} & =B_{b(e q)}+s_{1} e^{-\lambda_{1} t}+s_{2} e^{-\lambda_{2} t}
\end{aligned}
$$

where

$$
\begin{aligned}
& \lambda_{1,2}=\frac{1}{2}\left(\left(k_{a}^{\prime}+k_{b}^{\prime}+k_{a}\left[A^{\circ}{ }_{a}\right]+k_{b}\left[A^{\circ}{ }_{b}\right]\right)\right. \\
& \mp\left[\left(k^{\prime}{ }_{a}+k^{\prime}{ }_{b}+k_{a}\left[A b^{\circ}{ }_{a}\right]+k_{b}\left[A b^{\circ}{ }_{b}\right]\right)^{2}\right. \\
& \left.\left.-4\left(\mathrm{k}_{\mathrm{a}}^{\prime} \mathrm{k}_{\mathrm{b}}^{\prime}+\mathrm{k}^{\prime}{ }_{\mathrm{a}} \mathrm{k}_{\mathrm{b}}\left[\mathrm{Ab}^{\circ}{ }_{\mathrm{b}}\right]+\mathrm{k}^{\prime}{ }_{\mathrm{b}} \mathrm{k}_{\mathrm{a}}\left[\mathrm{Ab}^{\circ}{ }_{\mathrm{a}}\right]\right)\right]^{\xi}\right) \text {, }
\end{aligned}
$$

and

$r_{1}=-\frac{B_{a(e q)} \lambda_{2}-k_{a}\left[A b_{a}^{\circ}\right]}{\lambda_{2}-\lambda_{1}} \quad r_{2}=\frac{B_{a(e q)} \lambda_{1}-k_{a}\left[\mathrm{Ab}_{\mathrm{a}}^{\circ}\right]}{\lambda_{2}-\lambda_{1}}$

$s_{1}=-\frac{B_{b(e q)} \lambda_{2}-k_{b}\left[A b_{b}^{\circ}\right]}{\lambda_{2}-\lambda_{1}} \quad s_{2}=\frac{B_{b(e q)} \lambda_{1}-k_{b}\left[A b^{\circ}{ }_{b}\right]}{\lambda_{2}-\lambda_{1}}$

If $\mathrm{B}_{\mathrm{a}(\mathrm{eq})}$ and $\mathrm{B}_{\mathrm{b}(\mathrm{eq})}$ are determined as described in the previous section, a plot of $F$ vs. $t$ (Equation 35 ) is sufficient for the evaluation of the individual $k\left[\mathrm{Ab}^{\circ}\right]^{\prime} \mathrm{s}$ and $\mathrm{k}^{\prime \prime} \mathrm{s}$, since resolution of the curve into its exponential components will provide the necessary values of $\lambda_{1}, \lambda_{2},\left(r_{1}+s_{1}\right)$ and $\left(r_{2}+s_{2}\right)$. However, individual curves for $B_{a}$ and $B_{b}$ as a function of time may be obtained by withdrawing samples of the reaction mixture at various times and analyzing for the amount of bound insulin in each of the two complexes according to the procedures described in relation with Equations 28 and 29. The $\mathrm{k}^{\prime \prime}$ 's determined in each of these "dissociation" curves and the $k\left[\mathrm{Ab}^{\circ}\right]$ 's determined from the zero time slopes of $B_{a}$ vs. $t$ and $B_{b}$ vs. $t$ serve to check the values obtained from the analysis of $F$ vs. $t$ according to Equation 35.

Effect of dilution of antiserum. On dilution of antiserum, $\left[\mathrm{Ab}_{\mathrm{a}}^{\circ}\right]$ and $\left[\mathrm{Ab}_{\mathrm{b}}^{\circ}\right]$ are reduced by the same factor. Therefore, at tracer concentrations of insulin, dilution of antiserum does not alter the proportion between the more slowly and the more rapidly dissociating complexes.

Model: Insulin divalent or multivalent. At tracer concentrations of insulin, the transient state equations may be written, from Equations 11 and 12,

$$
\frac{d F}{d t}=-k\left[A b^{\circ}\right] F+k^{\prime}[\overline{\mathrm{AgAb}}]
$$

$$
\begin{aligned}
\frac{d[\overline{\mathrm{AgAb}}]}{\mathrm{dt}}=-k^{\prime}[\overline{\mathrm{AgAb}}] & -k_{\mathrm{c}}\left[\mathrm{Ab}^{\circ}\right][\overline{\mathrm{AgAb}}] \\
& +k\left[\mathrm{Ab}^{\circ}\right] \mathrm{F}+k^{\prime} c\left[\overline{\mathrm{AgAb}_{2}}\right]
\end{aligned}
$$

$\frac{d\left[\overline{\mathrm{AgAb_{2 }}}\right]}{\mathrm{dt}}=-k^{\prime}\left[\overline{\mathrm{AgAb}_{2}}\right]+k_{c}\left[\mathrm{Ab}^{\circ}\right][\overline{\mathrm{AgAb}}]$

$$
\frac{\mathrm{d}[\overline{\mathrm{AgAb}}]}{\mathrm{dt}} \ldots
$$$$
-k_{d}\left[\mathrm{Ab}^{\circ}\right]\left[\overline{\mathrm{AgAb}_{2}}\right]+k^{\prime}{ }_{d}\left[\overline{\mathrm{AgAb}_{3}}\right]
$$

If $[\overline{\mathrm{AgAb}}]$ is denoted by $a$, and $[\overline{\mathrm{AgAb}}]$ by $b$, solution (in the case of divalent insulin) of Equations 38 through 
40 for $F$, $a$ and $b$ as a function of time, employing the boundary conditions that at $\mathrm{t}=0 ; \mathrm{F}=1, \mathrm{a}=\mathrm{b}=0$ and at $\mathrm{t}=\infty ; \mathrm{F}_{(\mathrm{eq})}+\mathrm{a}_{(\mathrm{eq})}+\mathrm{b}_{(\mathrm{eq})}=1$, yields

$$
\begin{aligned}
& F=F_{(e q)}+r_{1} e^{-\lambda_{1} t}+r_{2} e^{-\lambda_{2} t} \\
& a=a_{(e q)}-\left(r_{1}+s_{1}\right) e^{-\lambda_{1} t}-\left(r_{2}+s_{2}\right) e^{-\lambda_{2} t} \\
& b=b_{(e q)}+s_{1} e^{-\lambda_{1} t}+s_{2} e^{-\lambda_{2} t}
\end{aligned}
$$

where

$$
\begin{aligned}
\lambda_{1,2}=\frac{1}{2}\left(\left(k\left[\mathrm{Ab}^{\circ}\right]+\right.\right. & \left.k_{\mathrm{c}}\left[\mathrm{Ab}^{\circ}\right]+\mathrm{k}^{\prime}+\mathrm{k}_{\mathrm{c}}^{\prime}\right) \\
& \mp\left[\left(\mathrm{k}\left[\mathrm{Ab}^{\circ}\right]+\mathrm{k}_{\mathrm{c}}\left[\mathrm{Ab}^{\circ}\right]+\mathrm{k}^{\prime}+\mathrm{k}_{\mathrm{c}}^{\prime}\right)^{2}\right. \\
& \left.\left.-4\left(\mathrm{k}^{\prime} \mathrm{k}_{\mathrm{c}}^{\prime}+\mathrm{k}_{\mathrm{c}}^{\prime} \mathrm{k}\left[\mathrm{Ab}^{\circ}\right]+\mathrm{kk}_{\mathrm{c}}\left[\mathrm{Ab}^{\circ}\right]^{2}\right)\right]^{\frac{1}{3}}\right)
\end{aligned} .
$$

and

$$
\begin{array}{ll}
s_{1}=-\frac{\lambda_{2} b_{(e q)}}{\lambda_{2}-\lambda_{1}} & r_{1}=\frac{\lambda_{2}\left(1-F_{(e q)}\right)-k\left[A b^{\circ}\right]}{\lambda_{2}-\lambda_{1}} \\
s_{2}=\frac{\lambda_{1} b_{(e q)}}{\lambda_{2}-\lambda_{1}} & r_{2}=-\frac{\lambda_{1}\left(1-F_{(e q)}\right)-k\left[A b^{\circ}\right]}{\lambda_{2}-\lambda_{1}} .
\end{array}
$$

The characteristics of "dissociation" curves will allow for identification of $\overline{\mathrm{AgAb}}$ and $\overline{\mathrm{AgAb}}$ with the slowly and rapidly dissociating complexes. If $\overline{\mathrm{AgAb}}$ dissociates less rapidly than $\overline{\mathrm{AgAb}} \mathbf{2}$ (i.e., $\mathrm{k}_{\mathrm{c}}^{\prime}>\mathrm{k}^{\prime}$ ), the slope of the dis-
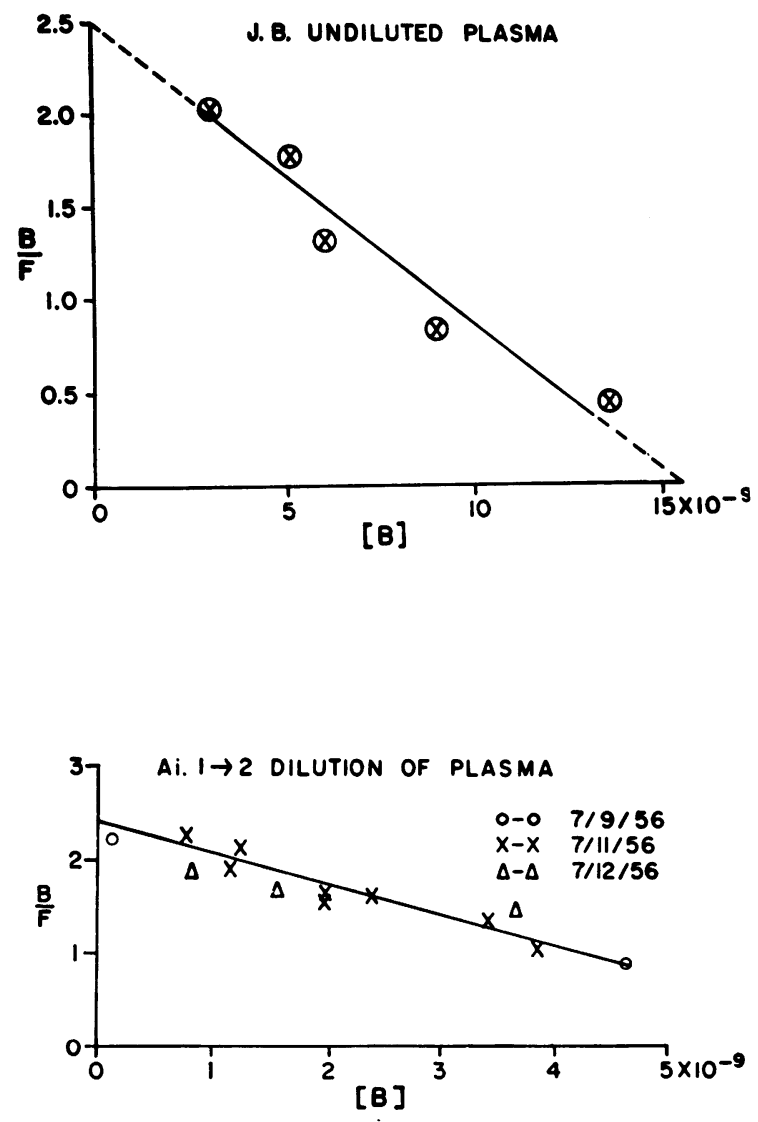

BOUND INSULIN-MOLS/LITER(M.W.6000)

Fig. 4. $\frac{B}{\mathrm{~F}}$ vs. B Curves in J. B. AND AI. Approximate a Straight Line

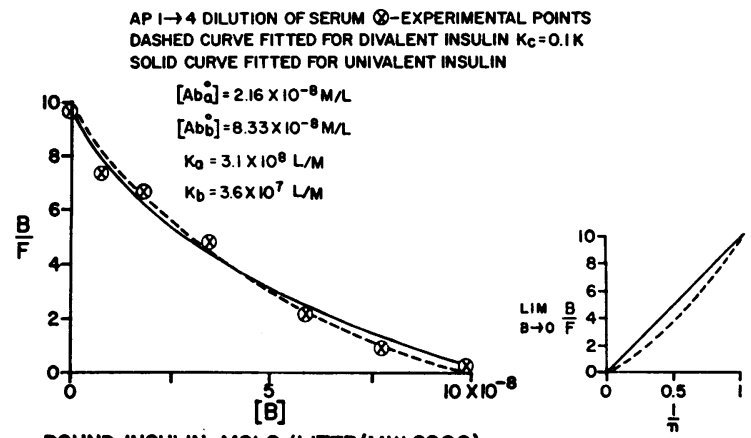

BOUND INSULIN-MOLS /LITER(M.W.6000)

Fig. 5. $\frac{B}{\mathrm{~F}}$ vs. B Data (Left) Fitted for Univalent and Divalent Insulin Models in Subject A. P. TheoRetical Curves of $\frac{B}{F}$ vs. $\frac{1}{N}$ in Same Subject (Right) FOR BOTH MODELS

Experimental $\frac{B}{\mathrm{~F}}$ vs. $\frac{1}{\mathrm{n}}$ curve for A. P. shown in Figure 7 .

sociation curve will become steeper with time (or, if the rates differ greatly, say by a factor of 10 or more, the curve will appear to approximate a single exponential component). Only if the converse is true (i.e., $\mathrm{k}^{\prime}>\mathrm{k}_{\mathrm{c}}^{\prime}$ ) can the initial segment of the dissociation curve have the sharpest slope. ${ }^{10}$ Unlike the case of univalent insulin reacting with two orders of antibody sites, the relative amounts of "univalent" and "divalent" complexes are not obtained simply from the extrapolation of the final component to zero time since the amounts in $a$ and $b$ at any time, $t$, following inhibition of recombination are described by the following equations :

$$
\begin{aligned}
\frac{d b}{d t} & =-k^{\prime}{ }_{c} b \\
\frac{d a}{d t} & =k^{\prime}{ }_{d} b-k^{\prime} a \\
b & =\bar{b} e^{-k^{\prime}{ }_{c} t} \\
a & =\bar{a} e^{-k^{\prime} t}+\frac{k^{\prime}{ }_{c} b}{k^{\prime}-k_{c}^{\prime}}\left(e^{-k^{\prime}{ }_{c} t}-e^{-k^{\prime} t}\right)
\end{aligned}
$$

where $\overline{\mathrm{a}}$ and $\overline{\mathrm{b}}$ are the amounts of $\mathrm{a}$ and $\mathrm{b}$, respectively, present at the time recombination is first inhibited. The concentration of bound insulin- $\mathrm{I}^{131}$ remaining at any time is, of course, the 5 sum, $a_{i}^{*}+b$. If the rates of dissociation of the two complexes are markedly different, the relative amounts of "univalent" and "divalent" complexes are approximately given by the coefficients of the two exponential terms in the expression for $a+b$.

Effect of dilution of antiserum. It follows from Equation 19 that the decrease in antibody concentration resulting

${ }^{10}$ For the condition $\mathrm{k}^{\prime}>\mathrm{k}_{\mathrm{c}}^{\prime}$, the initial slope may be sharper than, the same as, or shallower than the final slope, depending on the relative magnitudes of the rates and on the amounts in each form of the complex at the onset of dissociation. 
from dilution of the antiserum will be accompanied by a proportionate decrease in the ratio $\frac{\left[\overline{\mathrm{AgAb}_{2}}\right]}{[\overline{\mathrm{AgAb}}]}$ at tracer concentrations of insulin. The relative contributions of the two complexes to the total bound insulin at equilibrium will then differ at different serum dilutions, the ratio decreasing with dilution.

\section{RESULTS}

\section{Equilibrium state experiments}

In a few cases, plots of $\frac{B}{F}$ vs. $B$ could reasonably be fitted by a single straight line but the data available in these cases were incomplete (Figure 4). In most antiserums a curvilinear relationship was demonstrable and it was evident that a univalent insulin reacting with a single order of homogeneous antibody combining-sites would not suffice to account for the data. Moreover, the shapes of several of the curves were such that if observations had been less complete, particularly for values near one or the other axis, a straight line might have appeared to provide a satisfactory fit, which suggests that the linear relationship in Figure 4 was probably more apparent than real.

In some cases, the experimental data could be fitted almost equally well by assuming either a univalent insulin reacting with two different orders of antibody combining-sites or a divalent insulin reacting with a single order of antibody combining-sites (Figure 5). These were cases in which the slope of $\frac{B}{F}$ vs. B was not particularly steep for low values of B. For cases in which a steep slope in the region of low B was observed (e.g., D. C. and Pr., Figure 6) no fit was possible for the case of a divalent insulin and a single order of combining-sites even if $\mathrm{K}_{\mathbf{c}}$ was assumed to be very much greater than $\mathrm{K}^{\prime 11}$ however, a

11 This does not, of course, exclude the cases of divalent or multivalent insulin reacting with two or more orders of antibody combining-sites.
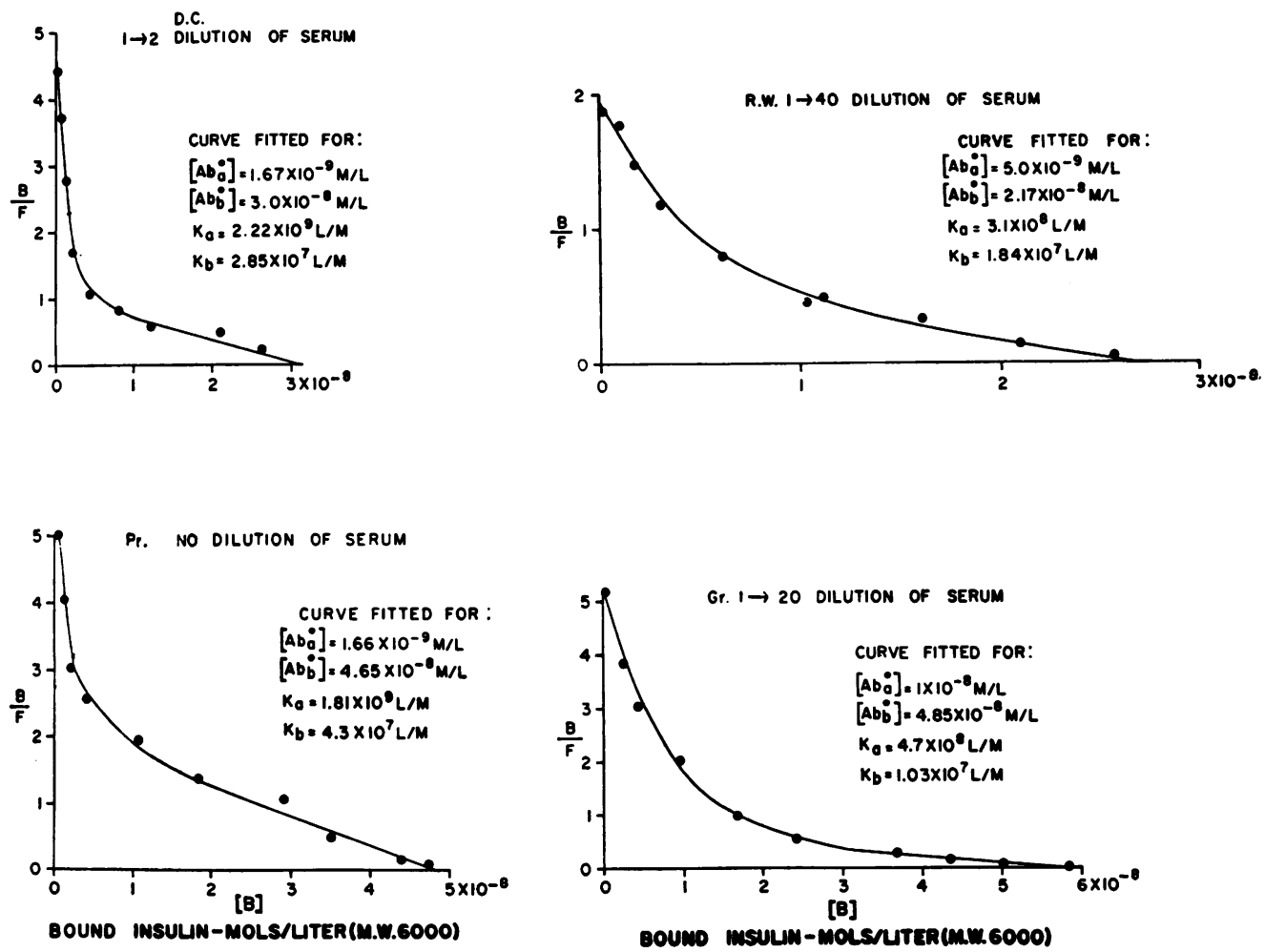

Fig. 6. $\frac{B}{\mathbf{F}}$ vs. B Curves for Nonresistant Subjects D. C. and Pr. and Resistant Subjects R. W. and Gr. Fitted for Univalent Insulin Reacting with Two Orders of Antibody ComBINING-SITES

Points are experimentally determined values. Curves are theoretical, fitted for values as indicated. 


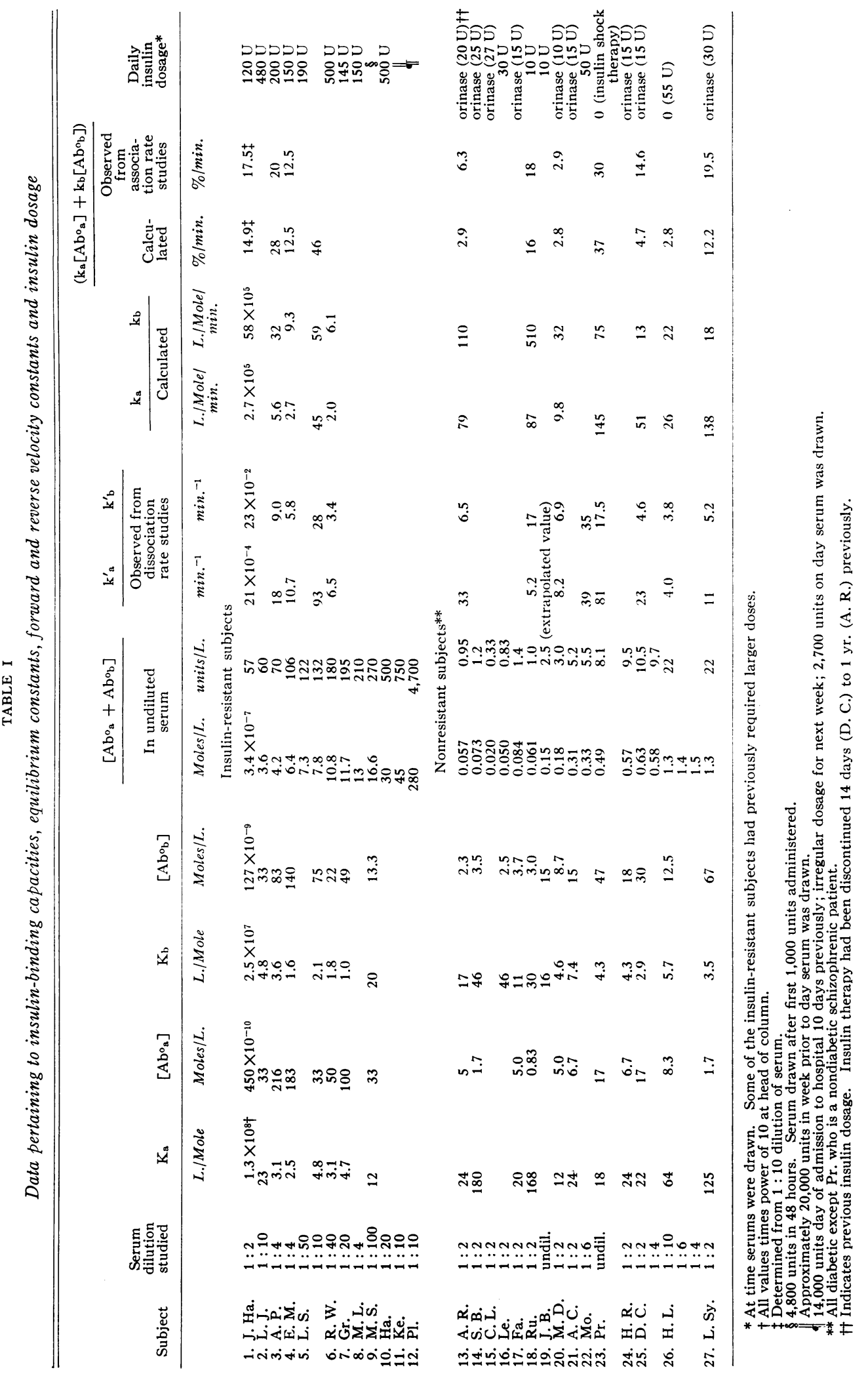



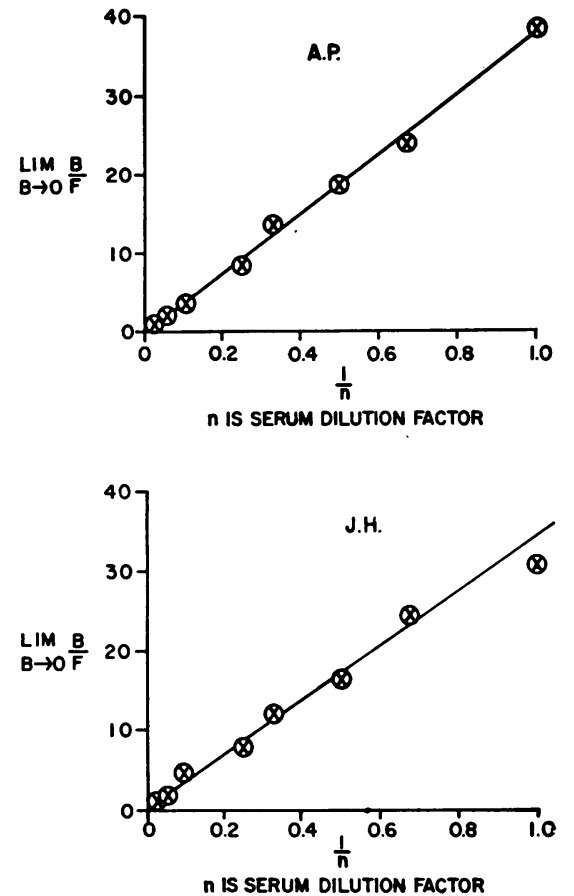

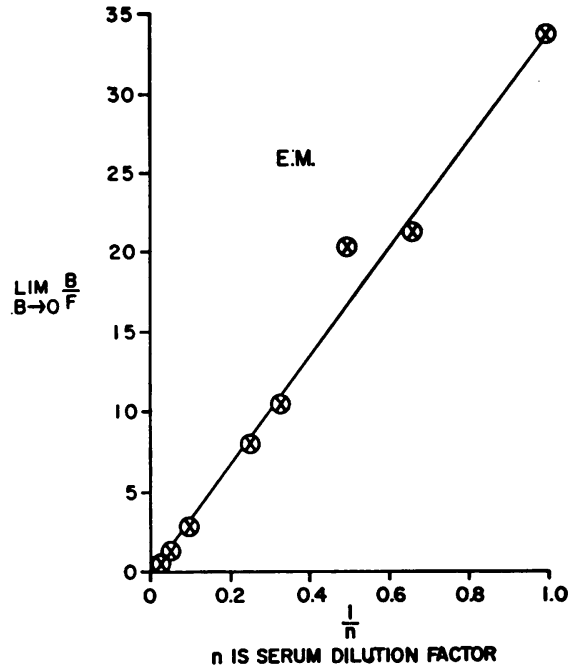

$n$ IS SERUM DILUTION FACTOR

Fig. 7. $\frac{\mathrm{B}}{\mathrm{F}}$ vs. $\frac{1}{\mathrm{~N}}$ IN Three Antiserums

Serum in J. H. taken at a different time than the serum for which data are reported in Table I and Figures 10 and 11. Refer to Figure 1 for departure from linearity expected for different $\frac{K_{c}}{K}$ values on the assumption that insulin is divalent.

good fit was always possible for the case of a univalent insulin reacting with two orders of antibody combining-sites (Table I, Figure 6). Calculations from the outlined method of curvefitting (see Appendices A and B) based on a univalent insulin reacting with two orders of antibody sites gave values for $K_{a}$ and $K_{b}$ of the order of $10^{8}$ to $10^{10}$ and $10^{7}$ to $10^{8} \mathrm{~L}$. per Mole, respectively (Table I). In many cases, if calculated for a divalent insulin, $\mathrm{K}$ would not have been less than one-third to one-half of the higher of the $\mathrm{K}$ value ranges given above.

Although exceptions are evident, the equilibrium constants were generally considerably higher in serums from nonresistant subjects than from resistant patients.

The determination of total available combining-sites is not dependent on the model used for analysis, since it is derived simply from the maximum amount of insulin bound at saturating concentrations of insulin (see Appendix B). Serums of high binding capacities may be diluted appreciably for these determinations. The val- ues obtained at different serum dilutions were generally in excellent agreement. Where antibody concentrations are low, undiluted serum may be used. On the assumption that one molecule of 6,000 molecular weight insulin is bound by one molecule of 160,000 molecular weight antibody, less than $1 \mathrm{~m} \mu \mathrm{g}$. absolute amount of antibody (in $0.1 \mathrm{ml}$. plasma) is detectable by those methods provided a high specific activity insulin- $\mathrm{I}^{131}$ is employed. If the weight ratio, insulin/antibody, is greater than $6,000 / 160,000$, the amount of detectable antibody is still lower. The technique employed here may well be the most sensitive method available for antibody detection yet described.

It is evident (Table I) that much greater quantities of insulin are bound in insulin-resistant patients than in serums from nonresistant patients. In addition to the cases presented in Table I, we have previously reported (1) on antiserums from 28 nonresistant insulin-treated subjects with maximum binding capacities not exceeding approximately 10 units per $L$. and have 
RATE OF ASSOCIATION OF INSULIN-I'II AT TRACER LEVELS WITH SERUM ANTIBOOY DETERMNED BY CHROMATOGRAPHIC SEPARATION OF BOUND \& UNBOUND INSULIN

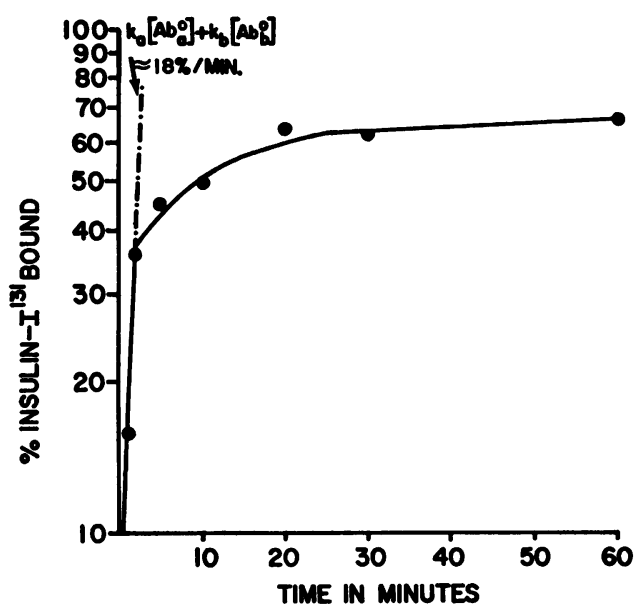

Fig. 8. RATE OF BINDING OF INSULIN-I ${ }^{131}$ IN Serum of SubJect Ru.

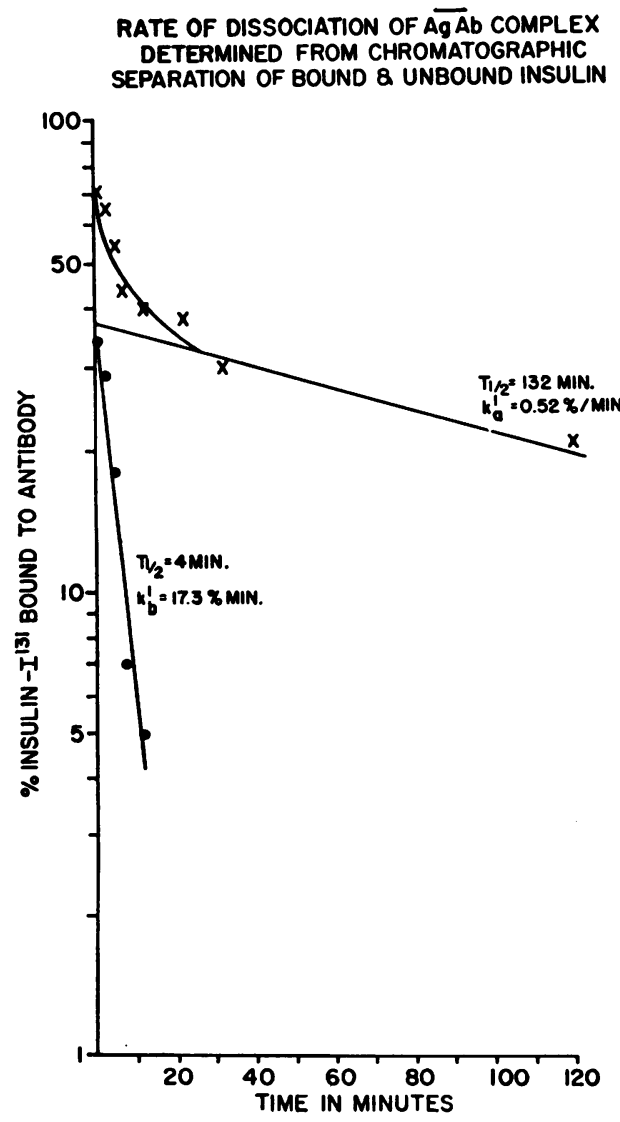

$a$ since examined many other similar cases. Only very occasionally have binding capacities as high as 20 units per L. been observed in serums of diabetic subjects requiring less than 75 units insulin daily for adequate control. In two such cases in the present series (H. L. and L. Sy.) binding capacities of 22 units per L. were observed. The case of $\mathrm{H}$. L. deserves special comment. This patient had maintained exceptionally stable control on 55 units PZI daily for the previous two years with fasting blood sugar levels of $200 \mathrm{mg}$. per $100 \mathrm{ml}$. and occasional $1+$ or $2+$ tests for sugar in the urine. On admission to the hospital PZI was withdrawn immediately, following which the patient maintained precisely his previous status with regard to fasting blood sugar concentrations and urinary spillage of glucose. He has not required insulin since its discontinuance over one year ago. It is of further

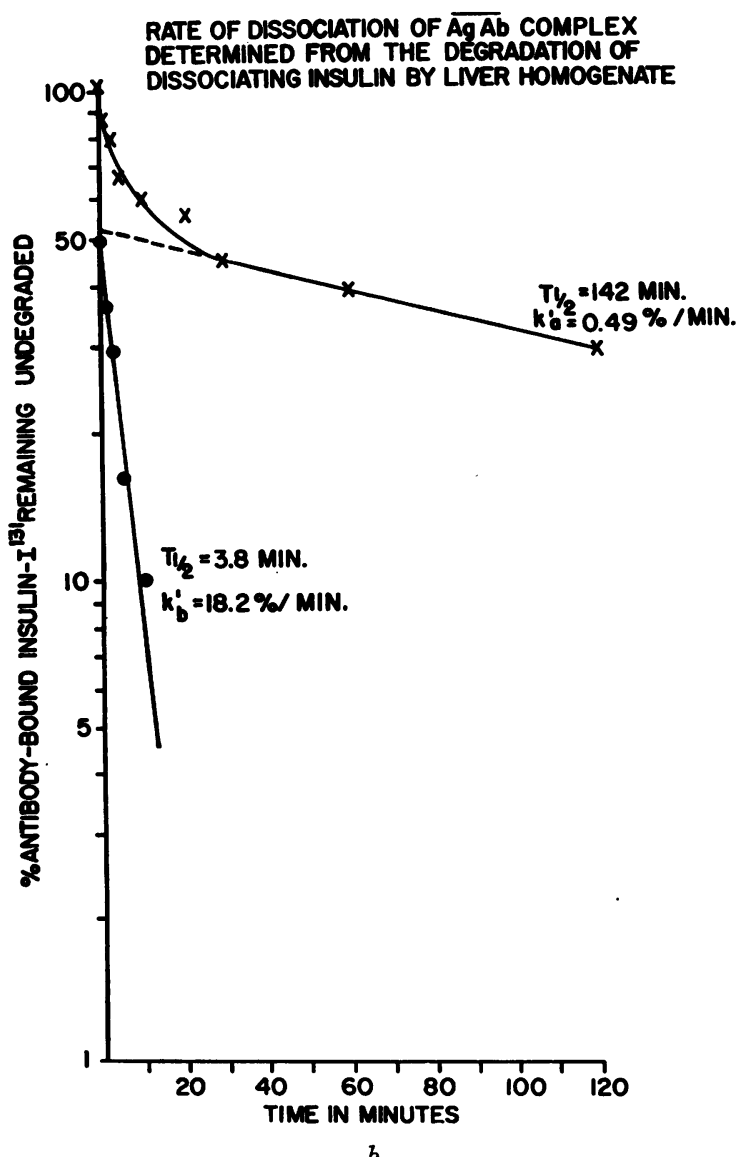

Fig. 9. Rate of Dissociation of Insulin-I131-Antibody Complexes in Serum of Subject Ru.: $a$ ) Determined by Paper Chromatography ; $b$ ) Determined from Rate of Degradation by Liver Insulinase 
interest that his antibody concentrations showed no significant decline over a period of six months. It seems reasonable to conclude that this patient was deriving little effect from the administered PZI and that if his endogenous insulin secretion had been inadequate to maintain satisfactory control, his exogenous insulin requirements might well have been considerably greater than the $\mathbf{5 5}$ units per day he was receiving.

Plots of $\frac{B}{F}$ vs. $\frac{1}{n}$ revealed only a linear relationship in all antiserums tested, three of which are shown in Figure 7.

\section{Transient state experiments}

In all cases studied there appeared to be two grossly different rates at which insulin at tracer concentrations became bound to antibody (Figure 8); i.e., on analysis, the approach to the equilibrium value took the form of the sum of two exponential components. Similarly, the formed antigen-antibody complexes were heterogeneous in that two rates of dissociation were observed (Figures 9a and b). The more rapid of these rates ranged from about 3 per cent per minute to 25 per cent per minute and the slow rates ranged from less than 0.01 per cent per minute to 1 per cent per minute in different antiserums (Table I). In one serum, the rates of dissociation were studied both with liver insulinase and by paper chromatography; the values for each of the two rates were in reasonable agreement by the two methods (Figures 9a and b).

In the last case and in most of the others, the observed rate of formation of complexes $\left(\mathrm{k}_{\mathrm{a}}\left[\mathrm{Ab}_{\mathrm{a}}{ }_{\mathrm{a}}\right]+\mathrm{k}_{\mathrm{b}}\left[\mathrm{Ab}_{\mathrm{b}}{ }_{\mathrm{b}}\right]\right)$ at zero time agreed reasonably well with the sum of the expected values calculated from each observed reverse velocity constant and $\frac{B}{\mathrm{~F}}$ ratio according to the formula: $\operatorname{Lim}_{B \rightarrow 0} \frac{B}{F}=K\left[\mathrm{Ab}^{\circ}\right]=\frac{k\left[\mathrm{Ab}^{\circ}\right]}{k^{\prime}}$ (Table I). The agreement in these cases is all the more gratifying since the values for the $\mathrm{K}\left[\mathrm{Ab}^{\circ}\right]$ 's were obtained from equilibrium studies whereas the $k^{\prime}$ 's were obtained from transient state experiments. However, in several experiments (A. R., D. C., L. Sy., Table I) the observed rate of complex formation was significantly greater than the calculated rate. It could not be determined whether these dis- crepancies were attributable to experimental errors or to defects in the theoretical models.

At equilibrium, in experiments with tracer concentrations of insulin- $\mathrm{I}^{131}$, frequently half or more than half of the bound insulin was in the slowly dissociating complex even when $\frac{B}{F}$ was as low as 0.65. However, after short periods of incubation, most of the complex was generally in the rapidly dissociable form, the ratio of slowly to rapidly dissociating components increasing with time of incubation (Figure 10). Transient state studies on the serum of $\mathrm{J}$. Ha. were analyzed according to the models of univalent insulin reacting with two orders of antibody sites (Equations 32 through 34, Figure 10) and of divalent insulin reacting with a single order of antibody sites (Equations 38 through 40; curve analysis not shown). The reaction rates of the two complexes calculated from $F$ vs. $t$ for both models were quite similar ${ }^{12}$ (Table II). Unfortunately, therefore, this experiment provided no grounds for choice between univalent and divalent insulin models. In both cases the calculated reverse velocity constant of the slowly dissociating component $\left(k^{\prime}{ }_{a}\right.$ or $k^{\prime}{ }_{0}$, respectively, in each of the two models) was greater than that observed, whereas the other calculated rate constants agreed quite well with directly observed values. The values for $\mathrm{K}_{\mathrm{a}}\left[\mathrm{Ab}_{\mathrm{a}}^{\circ}\right]$ and $\mathrm{K}_{\mathrm{b}}\left[\mathrm{Ab}^{\circ}{ }_{b}\right]$ obtained in the transient state studies according to the univalent insulin model were in good agreement with those derived from the equilibrium state analysis (Figure 11, Table III).

In all cases the initial segments of "dissociation" curves showed the sharpest slopes as in Figures 9 and 10.

Relative amounts of rapidly and slowly dissociating
complexes as a function of antibody concentration

It has been noted that if the two different complexes result from the combination of univalent insulin with each of two different antibody combining-sites, the ratio between the two complexes is not affected by dilution of the antiserum; thus, although the ratio of $\operatorname{Lim}_{B \rightarrow 0} \frac{B}{F}$ is lowered proportionately to the extent of dilution, the ratio

12 This is to be expected as a formal consequence of the mathematics of the two systems when the reaction rates of the two complexes differ markedly. 

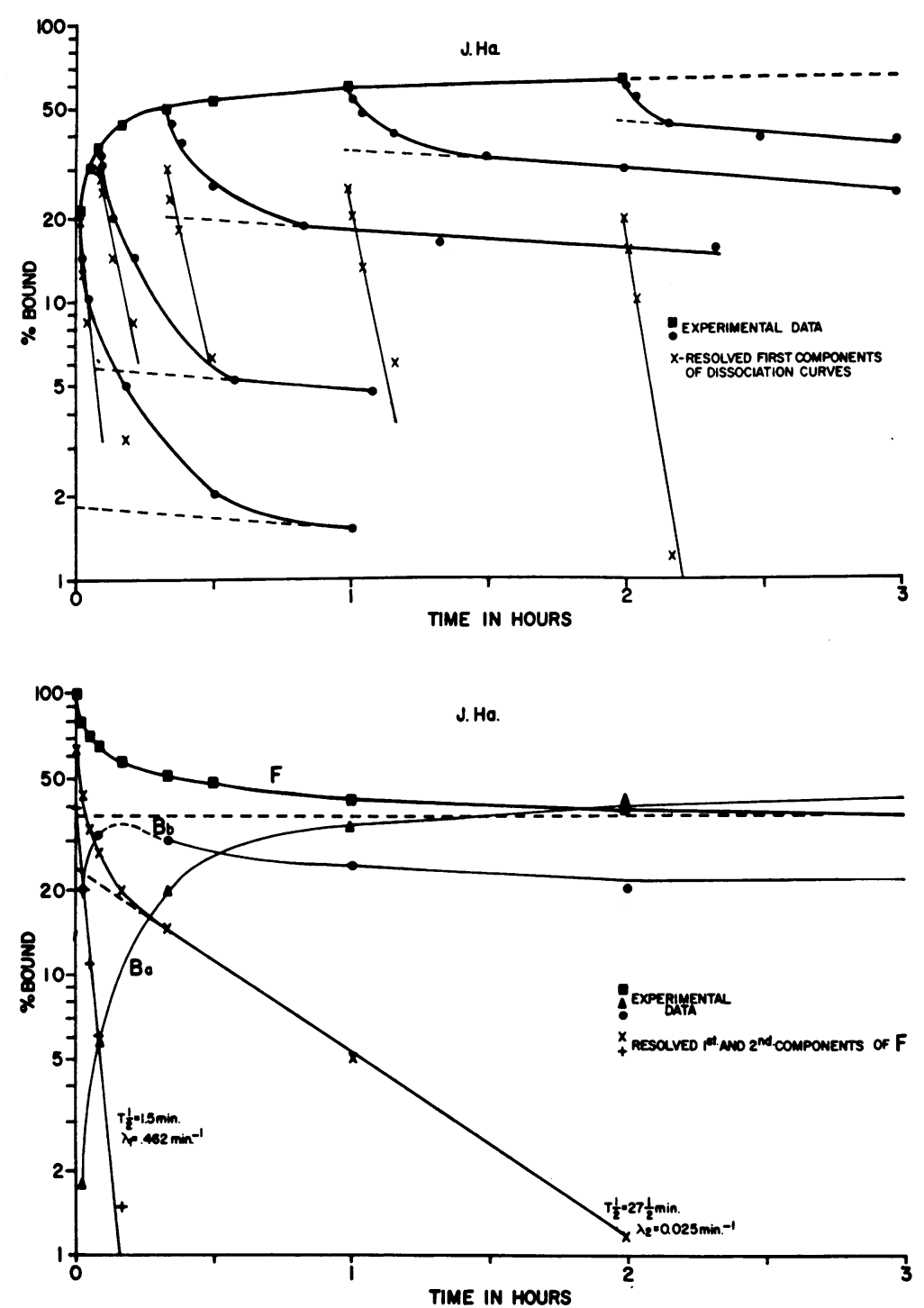

Fig. 10. Transient State Analysis in J. Ha.

The curve joining the solid squares in the upper half of the figure represents the rate of binding of tracer insulin-I ${ }^{131}$. At $0.5,5,20,60$ and 120 minutes, aliquots were removed to tubes containing swamping amounts of unlabeled insulin. The curves joining the solid circles represent the rates of dissociation of the insulin-I ${ }^{131}$ bound at these times. The latter curves were resolved into two components by extrapolating the terminal segments to the times marking onset of "dissociation." The ordinate values of the latter extrapolations are plotted as solid triangles in the lower half of the figure and represent the slowly dissociating component $\left(B_{\mathbf{a}}\right)$ according to the univalent insulin model. The values for $B_{b}$ are obtained by subtracting the values for $B_{a}$ from the values for total bound insulin- $\mathrm{I}^{131}$.

between rapidly and slowly dissociating forms should not be altered. If, on the other hand, insulin is divalent, the ratio between the two complexes, $\frac{\left[\overline{\mathrm{AgAb_{2 }}}\right]}{[\overline{\mathrm{AgAb}}]}$, will be expected to decrease proportionately with the dilution factor (cf. Equation 19). Since the experimental observations indicate that the more rapidly formed complex dissociates more rapidly and that, with time, the slowly dissociating complex increases 
partly at the expense of the rapidly dissociating complex, the divalent insulin model would require that $\overline{\mathrm{AgAb}}$ be the rapidly formed and rapidly dissociating complex and that $\overline{\mathrm{AgAb}_{2}}$ be the slowly dissociating complex. This follows also from the observation that the dissociation curves show the sharpest slopes initially. The ratio between slowly and rapidly dissociating complexes should then decrease proportionately with the dilution factor. To test the applicability of each of these models to the insulinantibody reaction, insulin in tracer concentrations was incubated with antiserum at four- to tenfold differences in dilution, and dissociation of the complexes in the equilibrium mixtures was studied by the methods described. The ratio between rapidly and slowly dissociating components and the rates of dissociation were essentially the same in different dilutions of the same anti-

TABLE II

Rates of association and dissociation of complexes calculated for univalent insulin reacting with two orders of antibody sites (mammillary system) and for divalent insulin reacting with a single order of antibody sites (catenary system)*

\begin{tabular}{|c|c|c|}
\hline & \multicolumn{2}{|c|}{$\begin{array}{l}1 \rightarrow 10 \text { Dilution of } \mathrm{J} . \mathrm{Ha} \text {. serum } \\
\text { Mammillary system (univalent insulin) }\end{array}$} \\
\hline & $\begin{array}{l}\text { Observed from association } \\
\text { and dissociation curves of } \\
B_{\mathrm{a}} \text { vs. } t, B_{b} \text { vs. } t\end{array}$ & $\begin{array}{l}\text { Calculated } \\
\text { from F vs. } t \text {. } \\
\mathrm{B}_{\mathrm{b}_{\text {eq }}} \text { and } \mathrm{B}_{\mathbf{a}_{\mathrm{eq}}}\end{array}$ \\
\hline $\begin{array}{l}\mathrm{k}^{\prime} \\
\mathrm{k}_{\mathrm{a}}^{\prime} \\
\mathrm{k}_{\mathrm{a}}\left[\mathrm{Ab}^{\circ}{ }_{\mathrm{a}}\right] \\
\mathrm{k}_{\mathrm{b}}\left[\mathrm{Ab}_{\mathrm{b}}\right]\end{array}$ & $\begin{array}{l}0.0021 \min ^{-1} \\
0.173-0.346 \text { (mean } 0.23) \\
0.015 \\
0.160\end{array}$ & $\begin{array}{l}0.015 \mathrm{~min}^{-1} \\
0.285 \\
0.0170 \\
0.170\end{array}$ \\
\hline
\end{tabular}

\begin{tabular}{|c|c|c|}
\hline & \multicolumn{2}{|c|}{ Catenary system (divalent insulin) } \\
\hline & $\begin{array}{c}\text { Observed and } \\
\text { calculated from } \\
\text { dissociation data }\end{array}$ & $\begin{array}{l}\text { Calculated } \\
\text { from F vs. t. } \\
\text { a eq and beq }^{\text {en }}\end{array}$ \\
\hline $\begin{array}{l}\mathrm{k}^{\prime} \mathrm{c} \\
\mathrm{k}^{\prime} \\
\mathrm{k}_{\mathrm{c}}\left[\mathrm{Ab}^{\circ}\right] \\
\mathrm{k}\left[\mathrm{Ab} \mathrm{b}^{\circ}\right]\end{array}$ & $\left.\begin{array}{l}0.0021 \mathrm{~min}^{-1} \\
0.23 \\
0.0040 \\
0.130\end{array}\right\}$ observed & $\begin{array}{l}0.0092 \mathrm{~min}^{-1} \\
0.290 \\
0.0177 \\
0.170\end{array}$ \\
\hline
\end{tabular}

* The calculated values from $F$ vs. $t$ for both models are to be compared with each other and with the observed values in the upper half of the table. Since the values for $\mathrm{k}\left[\mathrm{Ab}^{\circ}\right]$ and $\mathrm{k}_{\mathrm{c}}\left[\mathrm{Ab}^{\circ}\right]$ calculated from the observed dissociation data reflect errors in the latter, they are not directly comparable with other values.

$\dagger$ Calculations from dissociation data: $\bar{a}$ and $\bar{b}$ vs. $t$ were calculated from Equations 46 and 47 and extrapolated to yield $a_{e q}$ and $b_{e q} ; k\left[\mathrm{Ab}^{\circ}\right]$ and $k_{c}\left[\mathrm{Ab}^{\circ}\right]$ were then calculated from Equations 38 and 39 , respectively, for equilibrium conditions (i.e., $\frac{\mathrm{dF}}{\mathrm{dt}}=0 ; \frac{\mathrm{d}[\overline{\mathrm{AgAb}}]}{\mathrm{dt}}=0$ ) employing the mean values of $\mathbf{k}^{\prime}$ and $\mathbf{k}^{\prime}$ c observed from the dissociation curves.

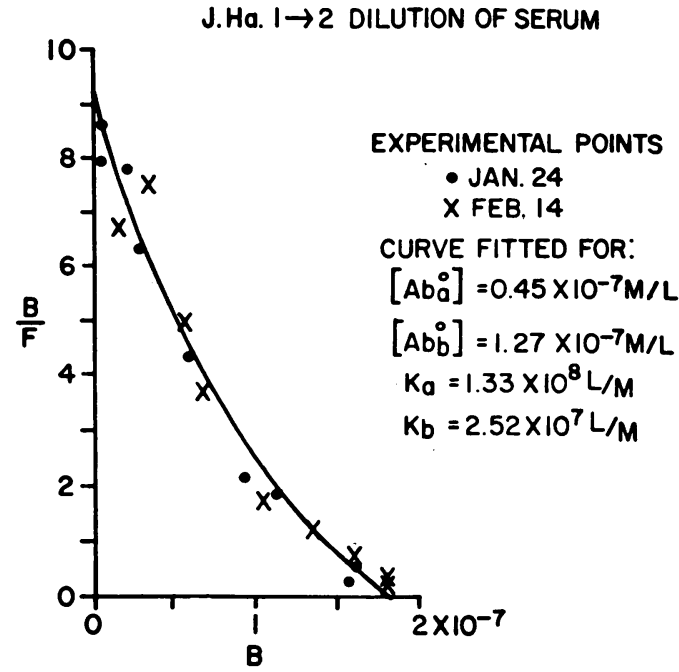

BOUND INSULIN-MOLS /LITER (M.W.6000)

Fig. 11. $\frac{B}{\mathrm{~F}}$ vs. B in Serum of Subject J. Ha.

serum even when the mixtures were preincubated for as long as 20 hours (Figure 12). The initial slopes of the dissociation curves were always steeper than the final slopes, which in itself would require, in the case of divalency of insulin, that $\mathbf{k}^{\prime}{ }_{\mathrm{c}}$ be less than $\mathrm{k}^{\prime}$.

As expected, the ratio between slowly and rapidly dissociating components is lower at load insulin concentration than at tracer insulin concentration (Figure 12). This was to be expected with either of the postulated models.

\section{DISCUSSION}

The antigen-antibody system under study here is unusual in several respects. Nonprecipitability of the complexes was observed previously in antiserum obtained from nonresistant subjects (1) and had been attributed either to the extremely low concentrations of complexes or, alternatively, to the possibility that the insulin-

TABLE III

Comparison of equilibrium and transient state kinetic data for model of univalent insulin and two orders of antibody binding sites in J. Ha.

\begin{tabular}{|c|c|c|c|c|}
\hline & \multicolumn{2}{|c|}{ Dilution of serum } & \multicolumn{2}{|c|}{$\begin{array}{l}\text { Corrected for } \\
\text { undiluted serum }\end{array}$} \\
\hline & $\begin{array}{c}\begin{array}{c}1 \overrightarrow{\text { Equi- }} \\
\text { librium }\end{array} \\
\text {. }\end{array}$ & $\begin{array}{c}1 \rightarrow 10 \\
\text { Transient }\end{array}$ & $\begin{array}{c}\text { Equi- } \\
\text { librium }\end{array}$ & Transient \\
\hline $\begin{array}{l}\mathrm{K}_{\mathrm{a}}\left[\mathrm{Ab}^{\circ}{ }_{\mathrm{a}}\right] \\
\mathrm{K}_{\mathrm{b}}\left[\mathrm{Ab}^{\left.{ }{ }_{\mathrm{b}}\right]}\right]\end{array}$ & $\begin{array}{l}6.0 \\
3.2\end{array}$ & $\begin{array}{l}1.14 \\
0.60\end{array}$ & $\begin{array}{r}12 \\
6.4\end{array}$ & $\begin{array}{r}11.4 \\
6.0\end{array}$ \\
\hline
\end{tabular}



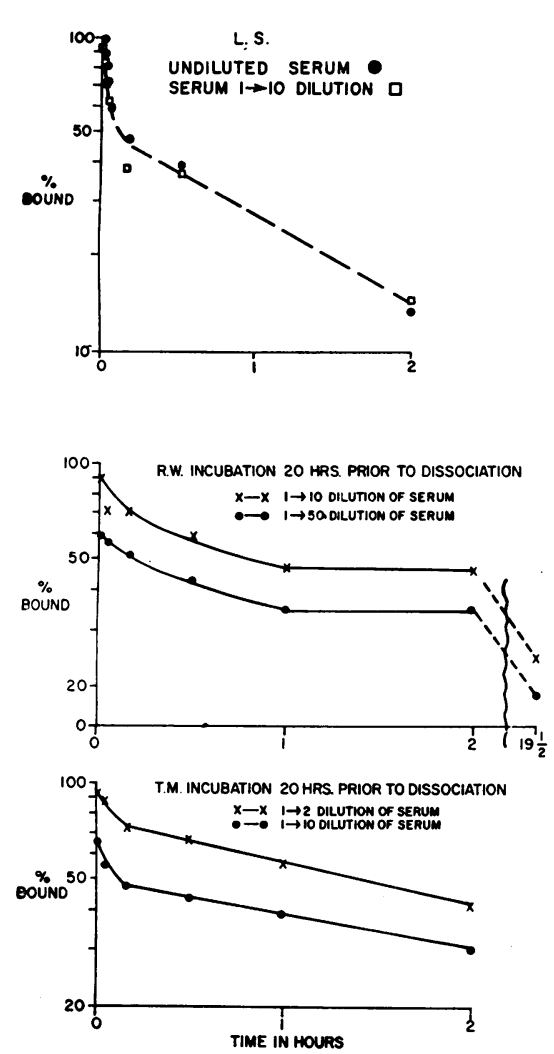

DISSOCIATION OF BOUND INSULIN - I'II

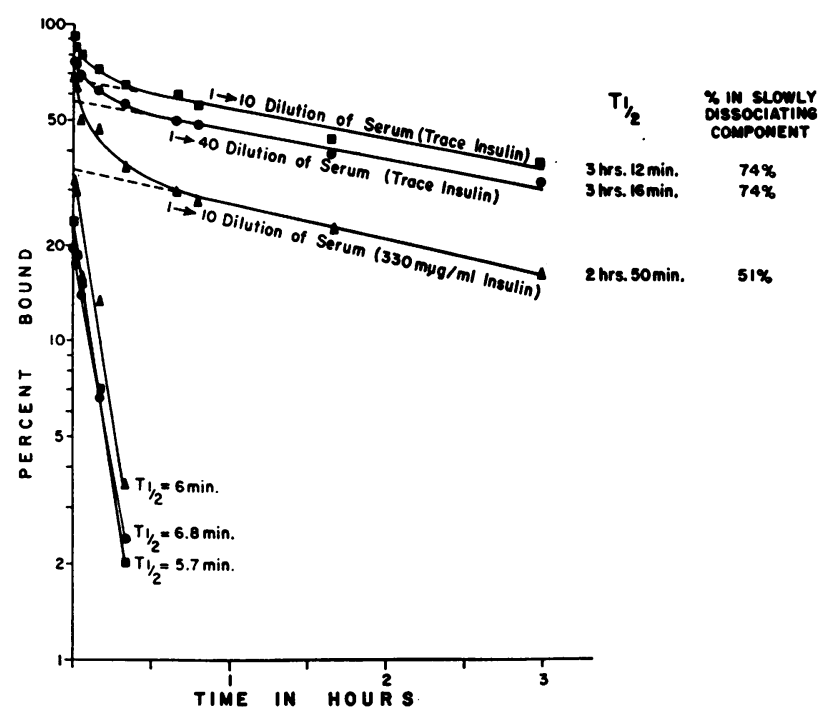

Fig. 12. "Dissociation" of Insulin-Antibody Complexes Formed at Different Dilutions of the SAME ANTiserums

Experiment on right in serum of Gr. taken at a different time than the serum for which data are reported in Table I.

binding antibody is univalent. However, in the present series, serums of high antibody titer, obtained from insulin-resistant patients, were analyzed throughout the range of marked antibody excess to marked antigen excess and precipitation could not be demonstrated even after prolonged refrigeration and centrifugation for 30 minutes at 5,000 G. Complexes containing $10 \mu \mathrm{g}$. insulin per $\mathrm{ml}$. have been studied so that concentrations of complexes probably exceeded $100 \mu \mathrm{g}$. per $\mathrm{ml}$. in these mixtures. With the rabbit antihuman serum albumin system it is possible to demonstrate, by paper chromato-electrophoresis (6), precipitability when complexes are present in a concentration of $1 \mu \mathrm{g}$. per $\mathrm{ml}$. The nonprecipitability of insulin-antibody complexes is therefore not due to inadequate concentrations in the mixtures employed. Although the alternative hypothesis previously offered, that insulinbinding antibody is univalent, may still be valid, univalency of antigen would suffice, equally well, to explain nonprecipitability. However, since most protein antigens are demonstrably multivalent or can be considered likely to be so on the basis of their structure even in the absence of experimental proof, the univalency of insulin as an antigen merits scrutinizing consideration.

Several different types of experiments have been performed to test whether insulin is univalent or multivalent. The results of some of these studies militate strongly against multivalency whereas the results of other experiments make multivalency appear unlikely. The evidence may be summarized.

1) On dilution of antiserum, the ratio $B / F$ at tracer insulin concentrations falls linearly with the reciprocal of the dilution factor. If insulin were multivalent, $B / F$ should be a function of some power of the dilution factor.

2) The ratio between rapidly and slowly dissociating complexes formed at trace insulin concentrations is not affected by four- to tenfold 
dilution of antibody concentration in individual antiserums. It has been pointed out that if "multivalent complexes" existed, they should be more prevalent at higher than at lower antibody concentrations and that the more dilute antiserum should contain a smaller proportion of slowly dissociating complexes. Furthermore, antiserum of very low antibody concentration should be virtually free of slowly dissociating complexes if insulin is multivalent: These requirements are incompatible with the experimental observations.

For reasons given below, the possibility of an insulin valency greater than two may be excluded almost with certainty. If, therefore, consideration is restricted to the possibility of divalency as opposed to univalency, the following points argue against divalency.

3) In all antiserums, the two single order rate constants of dissociation (for release of insulin) differ by a factor of 50 to 100 . As emphasized above, were the rapidly and slowly dissociating complexes to be correlated with "univalent complexes" and "divalent complexes," the latter would have to be identified with the slowly dissociating complexes. It then becomes difficult to explain why the rate of release of insulin from "divalent complexes" should be so much slower than from "univalent complexes" without postulating that the presence of a second antibody molecule increases, many fold, the strength of binding of insulin in the complex (i.e., $\mathrm{k}_{\mathrm{c}}^{\prime} \ll \mathrm{k}^{\prime}$ ). Although such a possibility is not out of the question, especially in view of the suggestion of Talmage (7) that inter-antibody linkages may be formed, it appears unlikely to us in the present instance.

4) The observation that most of the bound insulin may be in the slowly dissociating component even when as little as 40 per cent of trace concentrations of insulin is bound to antibody is incompatible with the slowly dissociating component being "divalent complex" unless $K_{c}$ is significantly greater than $\mathrm{K}$.

5) The experimental curves for $B / F$ vs. $B$ in the equilibrium studies could frequently not be fitted to theoretical curves derived from the model for a divalent insulin and a single order of antibody combining-sites. In these cases, the experimental curves were actually of a form com- pletely incompatible with such a model but were compatible with, and could be fitted closely by, a theoretical curve derived from the model of a univalent insulin reacting with two different antibody sites.

6) Finally, independent evidence that insulin is not multivalent is available from studies on the sedimentation velocities of $\mathrm{I}^{131}$-insulin-antibody complexes formed in undiluted serums of high titer in the region of marked antibody excess. These sedimentation velocities were found to be only 5 to 6 per cent greater than the sedimentation velocity of $I^{131}$-labeled $\gamma$-globulin (8). If the insulin-binding antibody does not differ significantly in size and shape from $\gamma$ globulin, these findings are inconsistent with the presence of complexes that contain more than a single antibody molecule regardless of the geometrical configuration of the complex, and are certainly incompatible with complexes containing more than two antibody molecules.

Thus, heterogeneity of antibody combiningsites rather than multivalency of insulin is favored as an explanation for the heterogeneity of insulinantibody complexes. The studies of Karush (9) have revealed that antibodies produced against haptenic dye groups react with the haptens in a manner consistent with the conclusion of Pauling, Pressman and Grossberg (10) that the distribution of free energy of binding can be described by a Gaussian error function. Therefore, even a single "order" of antibody combining-sites may be expected to react heterogeneously to some degree. However, the two widely different rates of dissociation of complexes in the insulin-antibody system cannot readily be interpreted simply in terms of a normal distribution of binding energies, but must be ascribed to groups.of distinctly different antibodies. That a distribution of energies within each group may exist can hardly be denied. The $\mathrm{K}$ values being measured simply represent average values within each group.

The evidence cited for the presence of two orders (at least) of antibody combining-sites has been indirect, derived essentially from exclusion of alternative models and from consistency of the experimental data with a theoretical model. However, in studies reported elsewhere (11) it has been shown that crystalline insulins obtained 
from different mammalian species show marked differences in direct reaction and in competitive cross-reactions with individual antiserums. Thus, beef and sheep insulins usually bind much more strongly than does pork or horse insulin and at certain concentrations the presence of beef insulin or sheep insulin produces, by competitive inhibition, a lower $\mathrm{B} / \mathrm{F}$ ratio for pork insulin- $\mathrm{I}^{131}$ and horse insulin- $\mathrm{I}^{131}$ than do pork insulin and horse insulin themselves at the same concentrations. When pork or horse insulin is added in concentrations sufficient to result in a very low $B / F$ ratio for these insulins, beef insulin$I^{131}$ may still be bound at a relatively high ratio. Yet, at low insulin concentrations, pork insulin is at least as effective as beef insulin in inhibiting the binding of pork insulin- ${ }^{131}$. These observations are incompatible with a single order of antibody combining-sites but are consonant with the presence of more than one order of antibody combining-sites, each having different affinities for each species-specific insulin. Inasmuch as commercial insulin preparations are composed of mixtures of pork and beef insulins, it is tempting to attribute the heterogeneity of antibody combining-sites to the different antigenic determinants present in beef and pork insulin. However, there is no experimental evidence on which to base such a correlation and, in fact, there is evidence that several different antibodies may be formed even in response to a single, relatively small, antigenic site. Landsteiner and van der Scheer (12) established the formation of discrete antibodies directed toward closely adjoining determinant groups and Kabat (13) has demonstrated heterogeneity of antibodies even to the simple repeating $\alpha 1,6$ glucose links of dextran, the antibody combining-sites varying in size from that complementary to a trisaccharide to that complementary to a straight chain hexasaccharide. Harris, Sanger and Naughton have shown that insulins derived from five different mammalian species differ only in positions 8 to 10 of the glycyl (A) chain (14). The sequence in these positions in beef insulin is ala, ser, val; in sheep insulin ala, gly, val; in pork insulin thr, ser, ileu and in horse insulin thr, gly, ileu. The differences in reaction with all these insulins which are identical except at the site under discussion, at least so far as amino acid sequence is concerned, suggest strongly that this site is an antigenic site. But antigenic determinacy could reside in several groups in this site and antibody molecules directed to several of these groups could differ strikingly in their affinity for insulin. It is therefore not possible to assign the different antibody combining-sites to beef insulin antibody and to pork insulin antibody specifically. Studies with serums from persons immunized with a single species insulin are obviously indicated. However, it is of some interest that rabbit anti-beef insulin serum ${ }^{13}$ forms heterogeneous complexes with beef insulin.

It should be emphasized here that evidence favoring univalency of insulin in its reaction with antibody does not necessarily imply that there is but a single antigenic site. The presence of two or more antigenic sites in insulin is quite compatible with univalency of insulin inasmuch as steric restrictions might well account for the inability of a single relatively small insulin molecule to bind antibody at more than a single antigenic site even if multiple sites are present.

It has been noted that the K's were generally lower in serums with higher antibody concentrations. Although there are definite exceptions, the general tendency would suggest that in this system, at least, a marked increase in antibody synthesis is associated with the production of antibody of lower affinity for the antigen.

Several other matters remain for critical comment. It has already been observed that if the antibody molecules are assumed to be divalent, the possibility cannot be excluded that the equilibrium constant for each site might be altered by the presence of an insulin molecule at the other site. It has not been feasible to evaluate this possibility, which is of importance only toward the side of antigen excess, nor are we aware of any relevant studies in any other immunologic system. It is clear that this complication may be ignored in the region of marked antibody excess and can in no way be considered responsible for the heterogeneity of complexes at trace insulin concentrations.

Another possible complication resides in the characteristic tendency of insulin to polymerize at high concentrations. In this work insulin has been assumed to be homogeneous and calcula-

${ }^{13} \mathrm{We}$ are indebted to Drs. E. Arquilla and A. Stavitsky for this antiserum. 
tions have been based on a molecular weight of 6,000 . Whether the individual insulin molecule weighs $6,000,12,000$ or 24,000 is of little importance in the results since a constant factor of 1 , one-half or one-fourth need only be applied to the calculated molar concentrations. However, should monomers, dimers, trimers, and so forth coexist in the mixtures being studied, analysis of the kinetics of reaction with antibody would become extremely complicated, for not only might a single antibody combining-site be complexed with one, two, three or more insulin monomer units but also, in the process of formation of dimers, trimers, and so forth, the antigenic sites might be masked or shielded in such a way as to inhibit or prevent reaction with the antibody. Conversely, if insulin polymerized into such a form as to leave the antigenic sites of several of the monomers exposed, it might be possible to form large antigen-antibody aggregates despite univalency of the insulin monomer. It has already been noted that ultracentrifugal sedimentation studies exclude the last possibility. Moreover, it appears unlikely that significant amounts of insulin polymers were ever present under the conditions of the experiments reported here. The studies of Fredericq (15) have provided evidence that, in concentrations $<0.1$ per cent, the 6,000 molecular weight monomer predominates above $\mathrm{pH} 9$ with preparations dialyzed free of zinc. ${ }^{14}$ In the present study the solutions employed never exceeded 0.001 per cent and usually were in the range 0.000001 to 0.00005 per cent. It seems highly improbable that the percentage of dimers in these solutions could ever have been significant.

Finally, a word may be said about the thermodynamics of the reaction of insulin with insulinbinding antibody. The standard free energy change $\left(\Delta \mathrm{F}^{\circ}\right)$, calculated from the equilibrium data according to the reaction isotherm,

$$
\Delta \mathrm{F}^{\circ}=-\mathrm{RT} \ln \mathrm{K}
$$

amounts to about minus 10 to $11 \mathrm{Kcal}$. per Mole and minus 11 to $14 \mathrm{Kcal}$. per Mole for reaction

\footnotetext{
${ }^{14}$ In the present studies duplicate runs in the usual veronal buffer, $\mathrm{pH} 8.6$, and in glycine buffer, $\mathrm{pH} 10$, have yielded identical results for binding of insulin to antibody. All insulin- $\mathrm{I}^{131}$ solutions were thoroughly dialyzed and it has already been noted that insulin- $\mathrm{I}^{131}$ showed no differences from unlabeled insulin with respect to binding by antibody.
}

TABLE IV

Thermodynamic constants in Subject M.S.

\begin{tabular}{|c|c|c|c|}
\hline $\begin{array}{c}\text { Antibody } \\
\text { sites }\end{array}$ & $\Delta \mathrm{F}^{\circ} 310^{\circ} \mathrm{K}$. & $\Delta \mathrm{H}^{\circ} 294^{\circ} \mathrm{K}$. & $\Delta \mathrm{S}^{\circ}$ \\
\hline & Kcal./Mole & Kcal./Mole & cal. $/^{\circ} \mathrm{K} . /$ Mole \\
\hline $\begin{array}{l}\text { "a" } \\
\text { "b" }\end{array}$ & $\begin{array}{l}-12.9 \\
-11.8\end{array}$ & $\begin{array}{l}-3.6 \\
-3.6\end{array}$ & $\begin{array}{l}30.0 \\
26.5\end{array}$ \\
\hline
\end{tabular}

with each of the two antibody combining-sites, respectively (see Appendix B). These values for the free energy of binding are considerably greater than those reported by Karush (9) for the azohaptenic dye-antibody systems (about 7 Kcal. per Mole) or for other protein-antiprotein systems (16). As indicated earlier, even if the equilibrium constant were calculated on the basis of a divalent insulin model, $-\Delta \mathrm{F}^{\circ}$ would still be in the range of 12 to $13 \mathrm{Kcal}$. per Mole in many cases.

Some preliminary studies on activation energy and on enthalpy changes have been made. It has been observed that both equilibrium constants are increased approximately twofold when the temperature of the reaction is lowered to $4^{\circ} \mathrm{C}$. and that at this temperature the reverse velocity constant is decreased by a factor of about 10. Because of the presence of two components in the complexes and the long periods of time required to complete observations at lower temperatures, the data necessary for reliable calculations are difficult to obtain. In one case followed for 72 hours, the equilibrium constants were just twice as great at $4^{\circ} \mathrm{C}$. as at $37^{\circ} \mathrm{C}$. The calculated values for $\Delta \mathrm{F}^{\circ}, \Delta \mathrm{H}^{\circ}$ and $\Delta \mathrm{S}^{\circ}$ are given in Table IV. In view of the very high binding energy in this antigen-antibody system, these studies should be of interest and are being pursued further.

A detailed discussion of the clinical significance of insulin-binding antibodies is not necessary here. However, it should be emphasized that a variety of factors must be taken into consideration before attempting to make a correlation between insulin requirements and insulin-binding capacities in individual cases. Among subjects with low binding capacities ( $<10$ units per $\mathrm{L}$. plasma) there is little demonstrable relationship between insulin dosage and antibody-binding activity simply because the latter is too small to be responsible for significant insulin wastage and 
because many of these patients do retain some ability to secrete endogenous insulin so that insulin dosage does not reflect insulin requirements accurately. However, it seems fairly certain that high binding capacities ( $>50$ units insulin per L. plasma) are likely to be accompanied by some degree of insulin resistance at least, and that the very highest binding capacities are associated with the most patent evidence of clinical resistance.

The question that must be asked is-How does the presence of insulin-binding antibodies result in an increase in insulin requirements? It might appear that antibody-induced insulin resistance should be no more than a transient phase if a steady state is eventually reached between association and dissociation of the antigen-antibody complexes since, even in the presence of high antibody concentrations, saturation of the antibody would eventually occur on continued insulin therapy. The transient nature of such insulin resistance may be noted on occasion when acute increases in insulin requirements occur, especially during infections, and when after a short period of massive insulin therapy there follows a period of repeated insulin reactions for days after discontinuation of insulin. The latter phenomenon has been interpreted (17) as due to gradual release of insulin from dissociating insulin-antibody complexes following the initial accumulation of high concentrations of insulin in these complexes. Nevertheless when such patients continue to require large doses of insulin for many months or years, it must be concluded that much of the insulin is being destroyed without the benefit of hormonal action. It seems reasonable to presume that such insulin wastage is attributable to the immunologic elimination of circulating antigen-antibody complexes and subsequent proteolytic destruction of the contained insulin moiety. Assuming a $6 \mathrm{~L}$. apparent volume of distribution for antibody, an insulin binding capacity of 200 units per L. plasma would mean a total insulinbinding capacity of 1,200 units. If, on an insulin dosage schedule required to maintain adequate control of diabetes, the antibody was on the average half saturated and if the insulin antibody complexes were eliminated from the circulation with a half-time of two days, ${ }^{15}$ insulin require-

\footnotetext{
15 This is the case with soluble complexes of the rabbit anti-bovine serum albumin and $\gamma$-globulin systems (18).
}

ments would be 210 units per day above those necessary for hormonal activity.

It is therefore evident that many factors other than antibody concentration per se will enter into determining the effect of antibodies on insulin requirements in individual cases. Among these may be listed: $a$ ) the rate at which insulin-antibody complexes are removed from the circulation which together with the rate of turnover of uncomplexed antibody will equal the rate of antibody synthesis in the steady state; $b$ ) the ratio of bound to free insulin at the free insulin concentration necessary for control of diabetes; $c$ ) the extent of saturation of the antibody at this ratio; and d) the rate at which complexes form and dissociate (which will determine how much of a given insulin dose will escape to the tissues before being bound or rebound to antibody). There may still remain many other factors not yet considered, but it is hoped that future study will aid in their elucidation.

\section{SUMMARY AND CONCLUSIONS}

1. Kinetic aspects of the reaction between insulin and insulin-binding antibody were studied with antiserums from insulin-resistant and nonresistant human subjects.

2. Insulin-antibody complexes are soluble throughout the range of marked antibody excess to marked antigen excess.

3. In antiserums from nonresistant subjects, insulin-binding capacities generally did not exceed about 10 units insulin per $\mathrm{L}$. serum, whereas insulin-binding capacities ranged from 50 units per L. to over 500 units per L. in antiserums from insulin-resistant patients.

4. The methods employed permit detection of less than $1 \mathrm{~m} \mu \mathrm{g}$. insulin-binding antibody, assuming the molecular weight of insulin to be 6,000 .

5. Methods are presented for the analysis and evaluation of equilibrium state and transient state data in systems composed of univalent or multivalent antigens reacting with a single order or with multiple orders of antibody combiningsites. Where necessary., antiserums were diluted appreciably for the purpose of slowing the rates of reaction sufficiently to permit evaluation of the rates of formation of complexes.

6. Heterogeneity of insulin-antibody complexes is revealed by both equilibrium state and tran- 
sient state studies. It appears, from the results of a variety of experimental approaches, that insulin is univalent in its reaction with antibody and that there are (at least) two orders of antibody combining-sites ("a" and " $b$ ") present in most antiserums, the " $a$ " term being given to the sites with the greater affinity for insulin. Univalency of insulin is not necessarily to be equated with mono-antigenicity inasmuch as binding of more than a single antibody molecule at different possible antigenic sites is conceivably prohibited by steric hindrance.

7. The ranges of values for the equilibrium constants, $\mathrm{K}$, the forward velocity constants, $\mathrm{k}$, and the reverse velocity constants, $\mathrm{k}^{\prime}$, where formation of the complex is taken as the forward direction, are as follows:

$$
\begin{aligned}
\mathrm{K}_{\mathrm{a}} & =1.3-180 \times 10^{8} \mathrm{~L} . \text { per Mole, } \\
\mathrm{K}_{\mathrm{b}} & =1.0-46 \times 10^{7} \mathrm{~L} . \text { per Mole; } \\
\mathrm{k}_{\mathrm{a}} & =2-145 \times 10^{5} \mathrm{~L} . \text { per Mole per minute, } \\
\mathrm{k}_{\mathrm{b}} & =6-510 \times 10^{5} \mathrm{~L} . \text { per Mole per minute; } \\
\mathrm{k}^{\prime}{ }_{\mathrm{a}} & =4-93 \times 10^{-4} \text { minute } \\
\mathrm{k}^{\prime}{ }_{\mathrm{b}} & =3.4-35 \times 10^{-2} \text { minute }
\end{aligned}
$$

8. The equilibrium constants were generally significantly higher in serums of nonresistant subjects (low antibody concentrations) than in serums of resistant subjects (high antibody concentrations). These findings imply that an increased rate of synthesis of insulin-binding antibody may be associated with the production of antibody of lower affinity for the antigen.

9. The standard free energy changes for the reactions with "a" and " $b$ " antibody sites are in the range, minus 11 to $14 \mathrm{Kcal}$. per Mole and minus 10 to $11 \mathrm{Kcal}$. per Mole, respectively. Preliminary data indicate a change in heat content of about $-3.5 \mathrm{Kcal}$. per Mole and a positive entropy change of 25 to 30 entropy units in the formation of insulin-antibody complexes.

10. The relationship of the results of these studies to certain aspects of clinical insulin resistance has been considered briefly.

\section{APPENDIX A}

Method of curve-fitting. A number of methods may be employed but the following has been found most expedient. Asymptotic straight line slopes are drawn to the curves at their extremities near the $x$ and $y$ axes. These slopes approximate $K_{b}$ and $K_{a}$, respectively. The sum of the ordinate intercepts of the two straight lines is then adjusted to equal the ordinate intercept of the experimental curve by "moving" both straight lines to the left keeping their slopes constant. The intercepts on the $x$ axis will now approximate the respective $\left[\mathrm{Ab}^{\circ}\right]^{\prime} \mathrm{s}$.

Using these values for the $\mathrm{K}^{\prime} \mathrm{s}$ and $\left[\mathrm{Ab}^{\circ}\right]$ 's, $\mathrm{B} / \mathrm{F}$ ratios for different values of $F$ are then calculated for each site from Equation 5. The curve of $\mathrm{B} / \mathrm{F}$ vs. $\mathrm{B}$ is then plotted using Equation 9 and compared with the experimental points. The K's and $\left[\mathrm{Ab}_{b}^{\circ}{ }^{\circ}\right.$ 's are now adjusted until the calculated curve makes a good fit to the experimental points. Little variation in the $\mathrm{K}$ 's and $\left[\mathrm{Ab}^{\circ}\right]^{\prime} \mathrm{s}$ is tolerated if the fit to the experimental points is not to be disturbed.

\section{APPENDIX B}

\section{Notes on experimental errors}

Maximum binding capacities. The presence of damaged components in insulin- $\mathrm{I}^{131}$ does not seriously affect the higher $\mathrm{B} / \mathrm{F}$ ratios but produces an increasing error as the ratios fall significantly below 1 . However, the maximum binding capacity is determined not from single mixtures at high concentration but from the best curve extrapolated from values at lower concentrations (and therefore higher percentages bound) to the $\mathbf{x}$ axis. Thus, while individual calculations at the highest concentrations might vary by as much as 50 per cent in the quantity of bound insulin, the maximum binding capacities determined by the best extrapolations are estimated to be in error by not more than 10 to 15 per cent as judged from the reproducibility of replicate determinations.

Concentrations of antibody combining-sites. These are determined from the fitted curves as described in Appendix $A$ and depend in some degree on the accuracy of all the points. However, $\left[\mathrm{Ab}^{\circ}{ }_{b}\right]$ generally comprised 80 per cent or more of the total antibody combining-sites and the error in this value is therefore of the same order as that in the maximum binding capacity. The value for $\left[\mathrm{Ab}_{\mathrm{a}}\right]$ is dependent on the initial slope of the $\mathrm{B} / \mathrm{F}$ vs. $\mathrm{B}$ curve. [Ab ${ }_{\mathrm{a}}$ ] (comprising only the smaller fraction of total antibody combining-sites) therefore is much more sensitive to experimental errors of the points close to the ordinate axis. It is estimated that the values for $\left[\mathrm{Ab}_{\mathrm{a}}^{\circ}\right]$ may be in error by as much as twofold.

Equilibrium constants. The accuracy of these values depends on the accuracy of the $\left[A b^{\circ}\right]^{\prime}$ s and $\underset{B \rightarrow 0}{\operatorname{Lim}} B / F$ ratios for each site. The error is directly proportional to the error of the $\operatorname{Lim}_{B \rightarrow 0} B / F$ ratio (which is small) and inversely proportional to the error of the $\left[\mathrm{Ab}^{\circ}\right]$. Accordingly, $K_{b}$ is probably accurate to \pm 10 to 20 per cent wherein $K_{a}$ may be in error twofold reciprocally to the error of $\left[\mathrm{Ab}_{\mathrm{a}}^{\circ}\right]$.

Standard free energy change. A twofold error in $\mathrm{K}$ produces an error of about 0.3 in $\Delta \mathrm{F}^{\circ}$. Since the latter ranged from about $9 \mathrm{Kcal}$. per Mole to $14 \mathrm{Kcal}$. per Mole, the percentage error probably does not exceed 2 to 3 per cent.

\section{ACKNOWLEDGMENTS}

We are indebted to Dr. Elvin A. Kabat for helpful comments and a critical review of the manuscript. We 
also wish to thank Frieda Steiner and Eve Spelke for secretarial assistance and the Department of Medical Illustration for the figures. We are indebted to the many physicians who supplied serums used in this study.

\section{REFERENCES}

1. Berson, S. A., Yalow, R. S., Bauman, A., Rothschild, M. A., and Newerly, K. Insulin- ${ }^{131}$ metabolism in human subjects: Demonstration of insulin binding globulin in the circulation of insulin treated subjects. J. clin. Invest. 1956, 35, 170.

2. Berson, S. A., and Yalow, R. S. Radiochemical and radiobiological alterations of ${ }^{131}$-labeled proteins in solution. Ann. N. Y. Acad. Sci. 1957, 70, 56.

3. Yalow, R. S., and Berson, S. A. Effect of X-rays on trace-labeled $I^{131}$ insulin and its relevance to biologic studies with I ${ }^{131}$-labeled proteins. Radiology 1956, $66,106$.

4. Yalow, R. S., and Berson, S. A. Apparent inhibition of liver insulinase activity by serum and serum fractions containing insulin-binding antibody. $\mathrm{J}$. clin. Invest. 1957, 36, 648.

5. Scatchard, G. The attractions of proteins for small molecules and ions. Ann. N. Y. Acad. Sci. 1949, 51,660 .

6. Berson, S. A., Yalow, R. S., and Newerly, K. Simultaneous quantitation of uncombined antigen and soluble and precipitable antigen-antibody complexes by paper electrophoresis (abstract). Fed. Proc. 1958, 17, 13.

7. Talmage, D. Personal communication.

8. Berson, S. A., and Yalow, R. S. Sedimentation velocity of soluble $\mathrm{I}^{131}$-labeled insulin-antibody complexes (abstract). Pittsburgh, Second Annual Meeting Biophysical Society, February 25-27, 1959.

9. Karush, F. Specificity of antibodies. Trans. N. Y. Acad. Sci. 1958, 20, 581.

10. Pauling, L., Pressman, D., Grossberg, A. L. The serological properties of simple substances. VII. A quantitative theory of the inhibition by haptens of the precipitation of heterogenous antisera with antigens and comparison with experimental results for polyhaptenic simple substance and for azoproteins. J. Amer. chem. Soc. 1944, 66, 784.

11. Berson, S. A., and Yalow, R. S. Species-specificity of human anti-beef, pork insulin serum. J. clin. Invest. 1959, 38, 2017.

12. Landsteiner, K., and van der Scheer, J. On cross reactions of immune sera to azo proteins. II. Antigens with azo components containing two determinant groups. J. exp. Med. 1938, 67, 709.

13. Kabat, E. A. Heterogeneity in extent of the combining regions of human antidextran. J. Immunol. 1956, 77, 377.

14. Harris, J. I., Sanger, F., and Naughton, M. A. Species differences in insulin. Arch. Biochem. 1956, $65,427$.

15. Fredericq, E. The association of insulin molecular units in aqueous solutions. Arch. Biochem. 1956, $65,218$.

16. Boyd, W. C. Fundamentals of Immunology, 3rd ed. New York, Interscience Publishers, 1956, p. 285.

17. Berson, S. A., and Yalow, R. S. Studies with insulinbinding antibody. Diabetes 1957, 6, 402.

18. Weigle, W. O. Elimination of antigen-antibody complexes from sera of rabbits. J. Immunol. 1958, 81, 204. 